The mindful lawyer: Investigating the effects of two online mindfulness programs on selfreported well-being in the legal profession

\author{
E. G. Nielsen, Ph.D. ${ }^{1}$ \\ John Paul Minda, Ph.D. ${ }^{1}$ \\ ${ }^{1}$ Department of Psychology \& The Brain and Mind Institute \\ Western University \\ London, Ontario, Canada
}

Address Correspondence to:

John Paul Minda, Ph.D.

Department of Psychology \& The Brain and Mind Institute

Western Interdisciplinary Research Building

Western University

London, ON, CA, N6A 5C2

519-661-2111 ext. 84689

jpminda@uwo.ca

Funding Sources: This work was supported by a doctoral postgraduate scholarship awarded to E. G. Nielsen by the Natural Sciences and Engineering Research Council of Canada (NSERC) and by an Insight Development grant awarded to J. P. Minda by the Social Sciences and Humanities Research Council of Canada (SSHRC; \#RES000162).

Conflict of Interest: None declared.

Acknowledgements: The authors would like to thank NSERC and SSHRC for providing the funding for this research. Thanks also to Jeena Cho and Karen Gifford for administering the interventions considered in these studies.

Ethical Considerations \& Disclosures: Both studies were conducted in accordance with ethics protocols approved by Western University’s Non-Medical Research Ethics Board (\#107342). 

Abstract
a. Objectives: Two studies were conducted to determine whether mindfulness meditation could be an effective tool for improving well-being among legal professionals - $\mathrm{a}$ population plagued by high rates of depression, anxiety, and stress.
b. Methods: Study 1. Legal professionals completed questionnaires before and after an 8- week mindfulness program. Study 2. Lawyers were randomly assigned to either an experimental or waitlist condition. Questionnaires were administered at the beginning of the study and after experimental participants had completed a 30-day intervention.
c. Results: Study 1. Participants reported significant improvements in mood, resilience, trait mindfulness, stress, anxiety, and depression over time. Study 2. Post-intervention, experimental participants reported better mood, lower levels of stress, and higher levels of non-reactivity and observing than waitlist participants.
d. Conclusions: Mindfulness and meditation may effectively improve well-being among legal professionals.

Keywords: mindfulness, meditation, well-being, stress management, lawyers 
The mindful lawyer: Investigating the effects of two online mindfulness programs on selfreported well-being in the legal profession

Mindfulness describes a quality of consciousness that emphasizes purposeful and nonjudgmental attention to, and acceptance of, the present moment. ${ }^{1-3}$ It is most often conceptualized as a psychological state that can be achieved via mindfulness practices (i.e., activities or techniques used to induce a state of mindfulness by promoting awareness of the present), though mindfulness can additionally be viewed as a relatively stable trait that varies from person to person; these related yet discrete concepts are referred to as state mindfulness and trait mindfulness, respectively. ${ }^{4}$ The relationship between trait and state mindfulness appears to be reciprocal, with the practice of mindfulness leading to changes in aspects of trait mindfulness ${ }^{5-8}$ and trait mindfulness influencing the relationship between states of mindfulness and psychological well-being. ${ }^{9,10}$ Meditation, which is an activity that involves the selfregulation of attention, ${ }^{11}$ is likely the most readily recognized mindfulness practice, though nonseated and non-meditative mindfulness activities (e.g., hatha yoga, mindful walking, and mindful eating) also exist.

Research has linked mindfulness to a multitude of favourable outcomes. A thorough review of these findings is available elsewhere. ${ }^{2,12}$ Broadly, the practice of mindfulness has been shown to decrease chronic pain, ${ }^{13-15}$ improve symptomatology of stress-related ${ }^{16-23}$ and anxietyrelated $^{24,25}$ conditions, reduce stress in otherwise healthy individuals, ${ }^{26-28}$ lower the risk of substance-related ${ }^{29}$ and depression-related ${ }^{30-34}$ relapse, enhance attention ${ }^{35-38}$ and working memory, ${ }^{35,39}$ and minimize the occurrence of cognitive biases. ${ }^{40-42}$ Positive relationships have also been found between psychological well-being and scores on trait mindfulness measures ${ }^{5}$ and meditation experience. ${ }^{43}$

Many explanations regarding the mechanistic relationships between mindfulness and mindfulness-related outcomes have been presented (e.g., see Baer $^{44}$ ). Because the practice of mindfulness involves attentional redirection and focus, attention is commonly implicated as an agent of change. Baer and colleagues ${ }^{9}$ suggest that self-directed attention has the potential to exacerbate psychological symptoms, but that mindfulness can reverse this relationship by allowing one to describe stimuli objectively, avoid judgement and reactivity, and mitigate rumination by encouraging attentional flexibility. Similar ideas have been proposed by Shapiro, Carlson, Astin, and Freedman, ${ }^{45}$ who note that intentional attention, combined with an attitude of nonjudgmentalness, allows for disidentification from and re-perception of one's personal experiences. Re-perception, in turn, facilitates well-being by promoting self-regulation, the clarification of values, sustained exposure to strong or difficult emotions and thoughts, and a reduction in habitual responding via increased cognitive-behavioural flexibility.

\section{Mindfulness at Work}

With numerous benefits being attributed to mindfulness, companies have been eager to explore its application in the workplace. Many major corporations now provide mindfulnessbased training programs to their employees ${ }^{46-49}$ and some have begun to commercialize their internally-developed interventions (e.g., Google's Search Inside Yourself Leadership Institute; https://siyli.org/). Commonly reported outcomes from workplace mindfulness programs include reductions in stress and pain and improvements in sleep quality, productivity, and decisionmaking abilities among workers. ${ }^{48,49}$ Some companies have even noted significant financial savings in health care costs due, presumably, in part to the introduction of workplace wellness initiatives. $^{49}$ 
Anecdotal reports of improved wellness and performance in the workplace following mindfulness training are largely supported by empirical studies (for a comprehensive review, see Lomas et al. ${ }^{50}$ ) Relative to inactive or waitlist controls, workplace-based mindfulness interventions have been found to increase levels of trait mindfulness, ${ }^{7,8,51-54}$ emotional intelligence, ${ }^{7}$ self-compassion, ${ }^{8,52,55}$ and psychological resilience, ${ }^{7,51}$ enhance job satisfaction, ${ }^{56}$ vigor, ${ }^{51}$ working memory capacity, ${ }^{8}$ psychological fulfilment, ${ }^{53}$ and mood; ${ }^{7}$ and reduce stress, ${ }^{7,8,51,53-55}$ emotional exhaustion, ${ }^{56}$ and sleep difficulties. ${ }^{52,54}$ Mindfulness training has also been found to enhance leadership abilities, ${ }^{7}$ increase empathy and decrease feelings of depersonalization and burnout, ${ }^{57}$ and mitigate declines in attention that are induced by jobrelated stress. ${ }^{58}$ Research further suggests that even a single mindfulness seminar can increase productivity but longer programs seem to be necessary for eliciting changes in attention, job satisfaction, and work-life balance. ${ }^{59}$

\section{Health and Wellness in the Legal Profession}

In the late 1980's, Benjamin and colleagues conducted a pair of studies assessing mental health in the legal profession; the results of both were troubling. The first, which involved three groups comprised of a total of 320 students and alumni from the University of Arizona Law School, found a dramatic increase in the severity of depressive symptoms throughout the course of the law program. ${ }^{60}$ At the time, depression was estimated to affect approximately 3-9\% of the population $^{61}$ and similar rates were found among those tested by Benjamin et al. in the summer prior to law school. However, $40 \%$ of students in their final year reported scores on the Beck Depression Inventory that fell within the top $2 \%$ of non-clinical norms. Though this number decreased over time, post-graduation rates of depression did not match pre-program levels, with $17 \%$ of alumni scoring at or above the 98 th percentile on this measure. This overall pattern of results was subsequently mirrored by a study of over 1,000 practicing lawyers from Washington state, of which $19 \%$ reported elevated levels of depression and $18 \%$ screened positive for alcohol abuse. $^{62}$

Health and wellness problems remain prevalent in the American legal profession. In 2016, a study of over 11,000 American law students found that $17 \%$ screened positive for depression and $37 \%$ screened positive for anxiety. Alcohol and illicit prescription drug use was also reported by $53 \%$ and $14 \%$ of students, respectively. ${ }^{63}$ Similarly, a survey of over 12,000 U.S. attorneys found above-normal levels of depression, anxiety, and stress occurring in 19-28\% of the sample and $11.5 \%$ reported that they had experienced suicidal ideation at some point during their career. ${ }^{64}$ Problematic levels of alcohol use were found in $20.6 \%$ of the lawyers and $36.4 \%$ screened positive on a measure of possible alcohol abuse and dependence; for comparison, a study of over 7000 surgeons found evidence of alcohol abuse using the same measure in only $15.4 \%$ of the sample. ${ }^{65}$

These studies imply that the legal profession continues to struggle with mental health challenges. Some suggest that this is because there are aspects of the job that can leave lawyers particularly prone to negative thoughts and emotions. ${ }^{66}$ Cognitively demanding tasks, for example, must be done with a high degree of perfection due to the lawyer's dual-responsibility for the reputation of their firm and the personal success of their clients. Competitiveness is encouraged, as are long hours, which can make it difficult to socialize or enjoy time away from the job. The practice of law also requires a certain degree of pessimism and detachment, as lawyers may need to consider worst case scenarios and contingency plans while simultaneously dealing with the darker aspects of human life, such as death, divorce, custody disputes, theft, and 
violent crime. At the same time, however, complete detachment must be avoided if one hopes to build a positive rapport with their clients.

Legal work can be very challenging and long hours spent immersed in difficult work and negative mindsets can fuel things like depression and dissatisfaction if healthy work/life boundaries are not maintained. ${ }^{66}$ Unfortunately, many lawyers who do face issues such as these are reluctant to seek help due to social stigma, concerns regarding privacy and confidentiality, and the potential for adverse professional repercussions. ${ }^{63,64}$ Fear of social and professional fallout, coupled with a belief that problems can be dealt with by oneself, may explain the prevalence of ineffective coping strategies such as alcohol use which, in turn, likely perpetuate and amplify the issues at hand.

\section{The Present Studies}

To be successful in the legal profession, one must possess great attention to detail, the ability to adaptively detach, and well-developed emotional intelligence skills (e.g., active listening and compassion) - all of which can be facilitated by mindfulness. It is unsurprising, therefore, that members of the legal profession have begun to explore the use of mindfulness in an effort to enhance functioning and improve well-being. Over the past 20 years, conferences and forums have been held to discuss the integration of mindfulness and law practices ${ }^{67-69}$ and many books and articles have been written on the topic. ${ }^{70-72}$ The American Bar Associationwhich developed a national task force on lawyer health and wellness ${ }^{73}$ in direct response to the work of Organ et al. ${ }^{63}$ and Krill et al. ${ }^{64}$ - lists many mindfulness-based resources on their website. ${ }^{74}$ There is, therefore, a precedent for investigating the impact of mindfulness on legal professionals; the present studies sought to do so by assessing outcomes associated with two mindfulness programs developed specifically for lawyers[1].

The studies outlined in this paper involved online data collection and interventions with online components. Web-based modalities were used because they have been found to be effective $^{75}$ and it was believed that lawyers would appreciate and benefit from the cost efficiency and flexibility that is afforded by internet-based programs. Both studies were exploratory because they represent the first time that either program has been examined empirically. However, based on results from prior work, mindfulness training was expected to improve mood, psychological resilience, and trait mindfulness, and decrease the severity of symptoms associated with depression, anxiety, and stress. Full datasets from both studies are available on Open Science Framework (OSF) at https://osf.io/tu74a/ (Study 1) and https://osf.io/qrxz8/ (Study 2).

\section{Study 1}

Study 1 employed a convenience sampling method and pre-post design to assess outcomes related to the 8-week mindfulness program outlined in Cho and Gifford's ${ }^{76}$ book, The Anxious Lawyer: An 8-Week Guide to a Joyful and Satisfying Law Practice Through Mindfulness and Meditation.

\section{Method}

\section{Participants}

Participants were recruited from a virtual book club sponsored by the National Association of Women Lawyers and Seyfarth Shaw LLP. The book club had arranged to read The Anxious Lawyer ${ }^{76}$ and members were asked to attend three webinars for continuing legal education (CLE) credits. Attendees of the first webinar were invited to participate in a study being conducted in conjunction with, yet separately from[2], the book club. Out of several hundred webinar attendees, 91 responded to at least one of the two assessments in the study. 
Individuals who participated in the study were not offered any compensation beyond the CLE credits obtained for attending the webinars.

\section{Intervention}

Participants were encouraged to read The Anxious Lawyer ${ }^{76}$ and to complete the accompanying 8-week program (see Supplemental Digital Content 1 for details). During the intervention, Cho and Gifford sent participants weekly emails that specified the book sections to be read and provided links to online guided meditations; this material was also available via a website (http://theanxiouslawyer.com/syllabus/).

\section{Self-Report Assessments}

Self-reports for both studies included a demographic survey, a series of questions regarding prior experience with meditation and other contemplative practices, and five psychological inventories selected based on their use in prior studies regarding mindfulness and well-being[3]. All measures were presented online using Qualtrics. ${ }^{77}$ Scales generally displayed adequate levels of internal consistency (for Study 1, $\alpha=.63-.92$; for Study 2, $\alpha=.64-.94$ ).

Perceived Stress Scale. The Perceived Stress Scale (PSS) ${ }^{78}$ is a 14-item questionnaire designed to measure one's perception of stressful events throughout the past month. Items are rated on a five-point scale ranging from 0 (never) to 4 (very often) and scores are calculated by reverse scoring positively worded questions and then taking the sum of all items. Scores range from 0-56, with high scores indicating a high level of perceived stress.

Positive and Negative Affect Schedule. The Positive and Negative Affect Schedule (PANAS) ${ }^{79}$ provides a measure of both positive and negative mood. Participants are presented with 20 mood descriptors (10 positive and 10 negative, intermixed) and are asked to indicate the extent to which they have felt each mood during the past month. Ratings are made on a scale of 1 (very slightly or not at all) to 5 (extremely) and scores for the positive and negative subscales are calculated by summing responses to the positive and negative words, respectively. Scores on each subscale range from 10-50, with high scores representing high levels of positive and negative mood.

Brief Resilience Scale. The Brief Resilience Scale (BRS) ${ }^{80}$ is a six-item measure of psychological resilience. Items are rated on a five-point scale ranging from 1 (strongly disagree) to 5 (strongly agree) and scores are calculated by reverse scoring negatively worded statements and taking the average of all responses. Scores range from 1-5, with high scores indicating a high degree of resilience.

Five Facet Mindfulness Questionnaire-24. The 24-item Five Facet Mindfulness

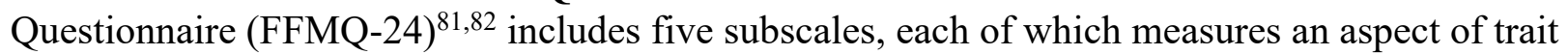
mindfulness - non-reactivity to inner experiences, observing, acting with awareness, describing, and non-judging of inner experiences. Items are rated on a five-point scale from 1 (never or very rarely true) to 5 (very often or always true) and scores are calculated by reverse scoring negatively worded statements and summing the items within each subscale. Scores on the observing subscale range from 5-20 and all other subscales have a range of 5-25. High scores on each subscale suggest high levels of each trait mindfulness component.

Depression Anxiety Stress Scales-21. The 21-item Depression Anxiety Stress Scales (DASS-21) ${ }^{83}$ includes three subscales that provide a measure of the severity of symptoms associated with depression, anxiety, and stress. Respondents are asked to consider their experience over the past week and rate items on a four-point scale from 0 (never) to 3 (almost always). Scores are calculated by summing the items within each subscale and multiplying the resulting values by 2 . Scores on each subscale range from $0-42$, with high scores representing a 
high severity of symptomatology associated with depression, anxiety, and stress. The DASS-21 also specifies ranges for the purpose of classifying scores as being indicative of symptoms that are normal, mild, moderate, severe, and extremely severe. The proportion of participants from each study that fall in each of these categories is outlined in Supplemental Digital Content 3.

\section{Procedure}

After the introductory book club webinar, participants were provided with a link for a Time 1 (T1) assessment. After clicking a button to indicate consent, participants were asked to enter their email address; email addresses were used to link responses across assessments and were replaced in the dataset with ID numbers after matching had occurred. Participants were then presented with the demographic survey, questions regarding prior contemplative experience, PSS, PANAS, BRS, FFMQ-24, and DASS-21, in that order. Following the T1 assessment, participants began the 8-week intervention. Instructions on how often to meditate throughout the program were not overly prescriptive but participants were advised to find a time that allowed them to practice as often as they could on a regular basis. Participants were reminded to make note of when and for how long they meditated each time that they practiced. At the end of the fourth week, a second webinar was conducted to provide members of the book club a chance to discuss The Anxious Lawyer and to ask questions. After the final week of the intervention, participants were provided with a link for a Time 2 (T2) assessment. With the exception of the demographic survey - which was replaced by a series of questions related to participation in the program - the T2 assessment was identical to the T1 assessment. Debriefing was done during a third book club webinar at the end of the program.

\section{Analyses}

All analyses in this paper employed a modified intention-to-treat (mITT) approach, whereby non-compliant participants (i.e., participants who reported a failure to meditate during the studies) were included. Missing data, however, was not imputed because imputation would have resulted in a substantial amount of estimated data, potentially complicating the interpretation of results. Per-protocol (PP) analyses excluding non-compliant participants were also conducted but detailed results are only presented in cases where the results differed from mITT analyses. All analyses were conducted in $\mathrm{R}^{84}$ and used an alpha of .05 .

Pearson's chi-square tests $\left(\chi^{2}\right)$ were used to compare discrete demographic variables. In cases where the cell expected values were not sufficient for performing a Pearson's chi-square test, ${ }^{85}$ a likelihood ratio chi-square test $\left(\chi_{\text {lr }}^{2}\right)$ was performed instead. Continuous demographic variables were compared using independent $t$-tests or, in cases of non-normality (assessed via a Shapiro-Wilk test), a Wilcox-Mann-Whitney test (z); in cases of homoscedasticity (assessed via a Levene's test), a Welch adjustment was applied. T1 and T2 comparisons were performed via paired samples $t$-tests or, in cases of non-normality, a Wilcoxon signed-rank test $(z)$. Chi-square tests and $t$-tests are accompanied by Cramer's $V$ and Cohen's $d$ effect sizes, respectively. Effect sizes for Wilcox-Mann-Whitney and Wilcoxon signed-rank tests were calculated as $r=z / \sqrt{n}$, where $n$ is the number of observations for the Wilcox-Mann-Whitney test and the number of observation pairs for the Wilcoxon signed-rank test.

Exploratory analyses were also conducted to determine whether change in each outcome measure - calculated as post-intervention scores - pre-intervention scores - was moderated by the number of minutes participants spent meditating per week. As suggested by Judd et al., ${ }^{86}$ moderation was tested by performing a regression analysis with change over time as the dependent variable and the suspected moderator as the independent variable. Regressions were 
conducted both pre- and post-outlier removal; outliers were identified using a standard cut-off of $1.5 \times$ the interquartile range.

\section{Results}

\section{Participant Attrition}

Ninety participants provided responses to the T1 assessment. Of these 90, 45 responded to the T2 assessment, resulting in an attrition rate of $50.00 \%$. Likelihood ratio chi-square tests indicated that participants who did and did not respond to the T2 assessment differed with respect to their education and the type of firm in which they worked; $\chi_{1 \mathrm{r}}{ }^{2}(2, N=90)=9.51, p=$ $.01, V=.31$ and $\chi_{\operatorname{lr}}^{2}(5, N=90)=11.11, p=.05, V=.31$, respectively. Pairwise comparisons employing a Holm-Bonferroni $p$-adjustment further revealed that rates of attrition were higher among those with a master's/doctoral degree (73.91\%) than among those with a professional degree (43.08\%) and were higher among those who reported working in a boutique firm (i.e., a small firm specializing in a particular niche; $100 \%)$ than among solo practitioners $(33.33 \%)$; $\chi^{2}(1, N=88)=6.46, p_{\text {adj }}=.03, V=.27$ and $\chi_{\mathrm{lr}^{2}}^{2}(1, N=24)=10.36, p_{\text {adj }}=.02, V=.58$, respectively.

\section{Modified Intention-to-Treat}

mITT analyses included the 45 participants who responded to both assessments; characteristics of these participants are presented in Supplemental Digital Content 4.

Comparisons. Descriptive statistics from each outcome measure are displayed in Table 1 and visualizations of score distributions are presented in Supplemental Digital Content 5. Analyses revealed a significant T1 to T2 decrease in scores on the PSS, the negative affect subscale of the PANAS, and all three subscales of the DASS-21; PSS, $t(44)=8.08, p<.001, d=$ 1.20; PANAS negative affect, $t(44)=4.78, p<.001, d=.71$; DASS-21 depression, $z=2.99, p=$ $.002, r=.45$; DASS-21 anxiety, $z=2.96, p=.003, r=.44$; and DASS-21 stress, $t(44)=5.81, p<$ $.001, d=.87$. Significant T1 to T2 increases were also noted on the positive affect subscale of the PANAS, the BRS, and all five subscales of the FFMQ-24; PANAS positive affect, $t(44)=-4.71$, $p<.001, d=-.70$; BRS, $t(44)=-3.26, p=.002, d=-.49$; FFMQ-24 non-reactivity, $t(44)=-5.82$, $p<.001, d=-.87$; FFMQ-24 observing, $z=-2.63, p=.01, r=-.39$; FFMQ-24 awareness, $t(44)=$ $-5.73, p<.001, d=-.85$; FFMQ-24 describing, $z=-3.29, p<.001, r=.49$; and FFMQ-24 nonjudging, $t(44)=-4.99, p<.001, d=-.74$.

Moderation. Two participant responses, corresponding to 262.50 and 280.00 minutes of meditation per week, were identified as outliers. Time spent meditating was not found to be a significant predictor of change on any of the outcome variables before or after outlier removal $(p$ $>.05$ for all).

\section{Per-Protocol}

Of the 45 participants who responded to both the T1 and T2 assessments, one indicated that they did not meditate at all throughout the program. For PP analyses, therefore, $n=44$. All results from PP analyses were found to be comparable to the results from mITT analyses (i.e., they did not differ with respect to significance).

\section{Discussion}

Participants took part in an 8-week, online mindfulness program and experienced a change in self-reported well-being that was consistent with our predictions and with the claim that a mindfulness intervention would have a net benefit. Increases in self-report measures of positive affect, psychological resilience, and aspects of trait mindfulness were observed, as were decreases in self-report measures of perceived stress; negative affect; and the severity of symptoms associated with depression, anxiety, and stress. Whether these changes were 
Table 1. Means and standard deviations $(M \pm S D)$ for each measure in Study 1.

\begin{tabular}{|c|c|c|}
\hline Measure & Time $1(M \pm S D)$ & Time $2(M \pm S D)$ \\
\hline \multicolumn{3}{|l|}{ Perceived Stress Scale* } \\
\hline & $31.44 \pm 8.64$ & $24.51 \pm 8.82$ \\
\hline \multicolumn{3}{|c|}{ Positive and Negative Affect Schedule } \\
\hline Positive Affect ${ }^{*}$ & $29.33 \pm 7.88$ & $33.76 \pm 6.52$ \\
\hline Negative Affect* & $28.24 \pm 8.31$ & $23.42 \pm 8.15$ \\
\hline \multicolumn{3}{|l|}{ Brief Resilience Scale ${ }^{*}$} \\
\hline & $3.03 \pm .91$ & $3.36 \pm .89$ \\
\hline \multicolumn{3}{|c|}{ Five Facet Mindfulness Questionnare-24 } \\
\hline Non-Reactivity $^{*}$ & $11.18 \pm 4.24$ & $14.29 \pm 3.70$ \\
\hline Observing* & $12.67 \pm 3.73$ & $13.67 \pm 3.55$ \\
\hline Awareness* & $13.22 \pm 4.39$ & $16.27 \pm 3.41$ \\
\hline Describing* & $17.07 \pm 3.63$ & $18.78 \pm 3.53$ \\
\hline Non-Judging* & $13.16 \pm 4.61$ & $16.29 \pm 4.33$ \\
\hline \multicolumn{3}{|c|}{ Depression Anxiety Stress Scales-21 } \\
\hline Depression $^{*}$ & $11.73 \pm 9.56$ & $8.40 \pm 8.37$ \\
\hline Anxiety ${ }^{*}$ & $9.02 \pm 7.13$ & $6.27 \pm 5.13$ \\
\hline Stress ${ }^{*}$ & $19.56 \pm 9.01$ & $13.20 \pm 8.88$ \\
\hline
\end{tabular}

Note. Values are from the modified intention-to-treat Time 1 and 2 comparison analyses. ${ }^{*} p \leq$ .05 .

specifically due to the meditation component of the program is unclear, as moderation analyses suggested that changes evoked by the program were independent from time spent meditating. Nevertheless, the Anxious Lawyer program does seem to have been effective in enhancing aspects of trait mindfulness and improving the well-being of those who participated in the study. The real-world efficacy of this program is supported, to some degree, by the convergence of results from mITT and PP analyses, although these findings should be interpreted with caution as the convenience sampling method used in this study precluded the inclusion of a control group.

Individuals with master's or doctoral degrees seemed to have been less likely to participate than those with professional degrees, though the attrition rate among those with master's and doctoral degrees may have been exaggerated by the relatively small T1 sample size for this group ( $n_{\text {master's/doctoral }}=23$ vs. $n_{\text {professional }}=65$ ). Differential rates of attrition between solo practitioners and those working in boutique firms may also have been influenced by differences in T1 sample sizes $\left(n_{\text {solo practitioners }}=18\right.$ vs. $\left.n_{\text {boutique firms }}=6\right)$ or, perhaps, boutique firm employees were less inclined to participate because they did not believe that the program would be relevant given the niche nature of their work[4].

\section{Study 2}

Study 2 assessed the effectiveness of Mindful Pause - a 1-month program adapted from The Anxious Lawyer ${ }^{76}$ by Cho. As in Study 1, Study 2 used a pre-post design, though Study 2 also implemented random assignment to a treatment or waitlist control group to allow for both between-group and within-group comparisons.

\section{Method}

\section{Participants}

One hundred employees from the American branch of an international law firm were recruited to participate in the Mindful Pause program in exchange for CLE credits. Program 
participants were randomly assigned to either an experimental or waitlist control group $(n=50$ for both). The experimental group was provided with a program start-date that was shortly after random assignment occurred and the waitlist control group was given a start-date that was after the experimental group's program was scheduled to end. Program participants were invited to participate in a study being conducted in conjunction with, yet separately from, the program. Of the 100 individuals who were recruited, 95 responded to at least one of the three assessments in the study. (A participant flowchart is presented in Figure 1.) Individuals who participated in the study were not offered any compensation beyond the CLE credits obtained for participating in the program.

Figure 1. Flow of participants in Study 2.

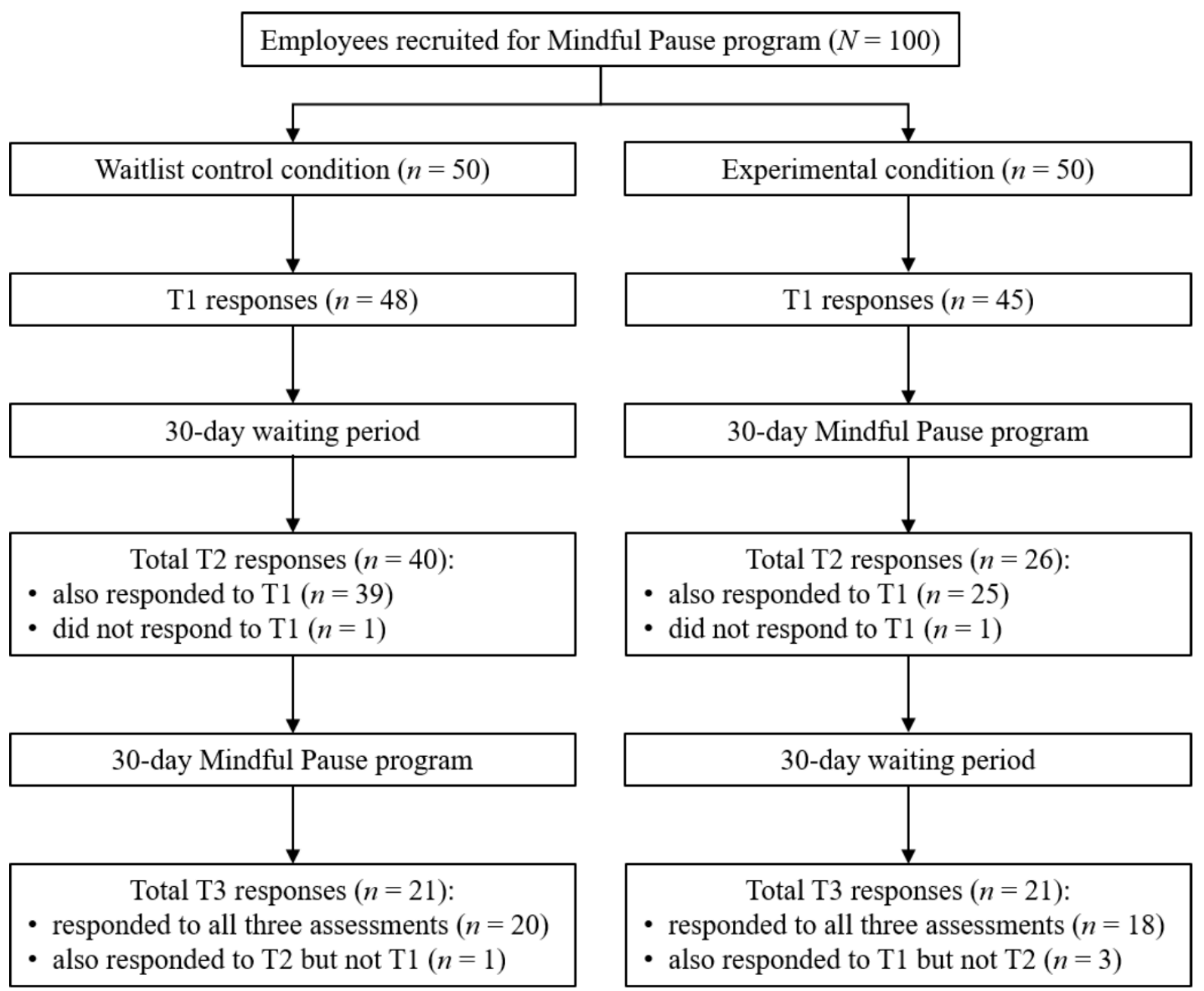

\section{Intervention}

Mindful Pause was designed to provide background information and the motivation to develop a daily mindfulness meditation practice. Each iteration of the Mindful Pause program was conducted over 30 consecutive days. Throughout the program, participants were sent daily emails containing brief information on topics including mindfulness and meditation, the management of stress and anxiety, and the use of cognitive resetting to address maladaptive 
patterns of thought. Emails also contained links to 6-minute, online guided meditations narrated by Cho. Additional program details are available at https://jeenacho.com/mindful-pause/.

\section{Procedure}

At the beginning of the study, all participants were provided with a link for a T1 assessment. After clicking a button to indicate consent, participants were asked to enter their email address; email addresses were used to link responses across assessments and were replaced in the dataset with ID numbers after matching had occurred. Participants were then presented with the T1 measures, as described in Study 1. Participants in the experimental condition were then invited to attend a 1-hour webinar that provided an introduction to mindfulness and an overview of the study timeline. Following the webinar, participants in the experimental condition began the 30-day intervention. Participants were advised to find a time that allowed them to practice as often as they could on a daily basis and were reminded to make a note of when and for how long they meditated each time that they practiced. Participants in the control condition were not given any instructions during this 30-day period but were informed that their program would begin in 30 days. After the experimental group had finished the program, all participants were asked to complete a T2 assessment. The T2 assessment was identical to the T1 assessment with the following exceptions: (1) the demographic survey was removed and, (2) for participants in the experimental condition, questions regarding program participation were added. The experimental group was then invited to attend a debriefing webinar while participants in the control condition were invited to attend an introductory webinar and begin the intervention. Participants in the experimental condition were not given any instructions during this 30-day period. After the control group had finished the program, all participants were asked to complete a Time 3 (T3) assessment. The T3 assessment was identical to the T2 assessment with the following exceptions: (1) questions regarding program participation were provided to participants in the control condition and (2) participants in the experimental condition were asked whether they had continued to practice meditation on their own in the 30 days since they had completed the program. Following the T3 assessment, participants in the control condition were invited to attend a debriefing webinar.

\section{Analyses}

An analysis plan preregistered on OSF proposed performing a 2 x 3 mixed ANOVA for each measure with condition as a between-group factor and time as a within-group factor. However, of the 100 participants enrolled in the study, only $38\left(n_{\text {Experimental }}=18\right)$ responded to all three assessments. Drawing generalizable conclusions from a small sample in a $2 \times 3$ mixed design is challenging. As a result, these analyses are presented in Supplemental Digital Content 6 and will not be discussed here. Instead, program-related effects were assessed via exploratory ANCOVAs, which compared condition-specific differences at T2 after accounting for preexisting differences at T1. This approach controls for group differences at T1 and provides greater power in randomized studies than can be achieved via a standard ANOVA. ${ }^{87}$ In cases of heteroscedasticity (assessed via a Levene's test) and/or heterogeneity of regression slopes (assessed by testing for an interaction between T1 scores and condition), Yuen's $t$-tests $\left(t_{\mathrm{Y}}\right)$ were implemented to compare trimmed means at specific levels of T1. Yuen's tests used a trim level of .20 and comparison points were chosen by first identifying all levels of T1 that were closely surrounded by 12 or more data points per group (as recommended by Mair and Wilcox ${ }^{87}$ ). Values of T1 $\left(X_{\mathrm{i}}\right)$ were deemed to be close to a potential comparison point $(x)$ if $\left|X_{\mathrm{i}}-x\right| \leq$ $f \times\left(\mathrm{MAD} / z_{.75}\right)$, where $\mathrm{f}$ is a smoothing parameter (set to 1 in these tests), MAD is the median absolute deviation (i.e., the median of $\left|X_{i}-\tilde{X}\right|$ ), and $z_{.75}$ is the .75 quantile of the standard 
normal distribution. ${ }^{88}$ This calculation was repeated, substituting each unique value of T1 for $x$. Values of T1 that were found to have at least 12 close points/group were identified and the minimum, median, and maximum values from that set were selected as the comparison points of interest. For each comparison point, close values of T1 and their accompanying T2 values (i.e., $X_{\mathrm{i}}, Y_{\mathrm{i}}$ observation pairs) were separated by group and each set of T2 values was trimmed. Groups were then compared via the means of these trimmed sets and Holm-Bonferroni $p$-adjustments were used to account for the multiple comparisons being performed. ANCOVAs and Yuen's $t$ tests are accompanied by generalized eta-square $\left(\eta_{G}^{2}\right)$, and explanatory power $(\xi)$ effect sizes, respectively.

\section{Results}

\section{Participant Attrition}

Ninety-three participants $\left(n_{\text {Experimental }}=45\right)$ provided responses to the T1 assessment. Of these 93, $64\left(n_{\text {Experimental }}=25\right)$ responded to the T2 assessment, resulting in an overall attrition rate of $31.18 \%$ between the first two time periods. Chi-square and independent t-tests indicated that attrition was significantly related to condition and age; $\chi^{2}(1, N=93)=7.15, p=.01, V=.28$ and $t(91)=-2.05, p=.04, d=-.50$, respectively. More specifically, the rate of T1 to T2 attrition was higher in the experimental condition (44.44\%) than in the control condition $(18.75 \%)$ and participants who did not respond to the T2 survey $(M=44.28, S D=8.03)$ were found to be younger than those who did $(M=48.61, S D=9.99)$.

\section{Modified Intention-to-Treat}

Comparisons. mITT T2 comparisons included the 64 participants who responded to both the T1 and T2 assessment; characteristics of these participants are presented in Supplemental Digital Content 4. Descriptive statistics from ANCOVAs and Yuen's t-tests are displayed in tables 2 and 3, respectively and visualizations of these tests are presented in Supplemental Digital Content 5 . None of the characteristics were found to differ significantly across conditions among these 64 participants $(p>.05$ for all).

After adjusting for differences in T1 scores, experimental participants were found to have significantly lower T2 scores on the PSS, the negative affect subscale of the PANAS, and the stress subscale of the DASS-21 than control participants; $F(1,61)=11.65, p=.001, \eta_{\mathrm{G}}{ }^{2}=.16$; $F(1,61)=9.04, p=.004, \eta_{\mathrm{G}}{ }^{2}=.13$; and $F(1,61)=7.94, p=.01, \eta_{\mathrm{G}}{ }^{2}=.12$, respectively. Compared to control participants, experimental participants also reported significantly higher T2 scores on the positive affect subscale of the PANAS and the observing subscale of the FFMQ$24 ; F(1,61)=5.82, p=.02, \eta_{\mathrm{G}}{ }^{2}=.09$ and $F(1,61)=18.26, p<.001, \eta_{\mathrm{G}}{ }^{2}=.23$, respectively. T2 differences were not observed on the BRS or on the non-reactivity, awareness, and describing subscales of the FFMQ-24 ( $p>.05$ for all). A non-parametric approach was used to assess T2 differences on the non-judging subscale of the FFMQ-24 and the depression and anxiety subscales of the DASS-21 because regression slopes were found to be heterogeneous (FFMQ-24 non-judging) and residuals were found to be heteroscedastic (DASS-21 depression and anxiety). However, no significant condition-specific differences were observed between T2 scores on any of these scales at any of the T1 values considered ( $p>.05$ for all).

Moderation. mITT regression analyses included the 25 experimental participants from the mITT comparison analyses and the 21 control participants who responded to both the T2 and T3 assessments; characteristics of these control participants are presented in Supplemental Digital Content 4. One control participant was omitted from analyses involving the FFMQ-24 and the DASS-21 because they failed to respond to these scales in the T3 assessment.

Time spent meditating was found to be a significant predictor of change in scores on both 
Table 2. Time 1 grand means $\left(M_{\mathrm{G}}\right)$ and Time 2 adjusted means and standard errors $\left(M_{\text {adj }} \pm S E\right)$ for measures analyzed via analysis of covariance tests in Study 2.

\begin{tabular}{|c|c|c|c|}
\hline Measure & Time $1\left(M_{\mathrm{G}}\right)$ & $\begin{array}{c}\text { Control } \\
\text { Time } 2\left(M_{\text {adj }} \pm S E\right)\end{array}$ & $\begin{array}{c}\text { Experimental } \\
\text { Time } 2\left(M_{\mathrm{adj}} \pm S E\right)\end{array}$ \\
\hline Perceived Stress Scale & 27.77 & $26.40 \pm .90$ & $21.46 \pm 1.13$ \\
\hline $\begin{array}{r}\text { Positive and Negative A } \\
\text { Positive Affect } \\
\text { Negative Affect }\end{array}$ & $\begin{array}{r}\text { Schedule } \\
32.30 \\
24.36\end{array}$ & $\begin{array}{l}31.85 \pm .72 \\
23.43 \pm .68\end{array}$ & $\begin{array}{l}34.63 \pm .90 \\
20.17 \pm .85\end{array}$ \\
\hline Brief Resilience Scale & 3.40 & $3.48 \pm .07$ & $3.66 \pm .09$ \\
\hline $\begin{array}{c}\text { Five Facet Mindfulness } \\
\text { Non-Reactivity } \\
\text { Observing* } \\
\text { Awareness } \\
\text { Describing }\end{array}$ & $\begin{array}{c}\text { tionnaire-24 } \\
14.05 \\
12.81 \\
14.58 \\
17.83\end{array}$ & $\begin{array}{l}14.61 \pm .46 \\
12.61 \pm .25 \\
15.29 \pm .40 \\
18.09 \pm .38\end{array}$ & $\begin{array}{l}16.05 \pm .58 \\
14.32 \pm .31 \\
16.43 \pm .50 \\
18.38 \pm .48\end{array}$ \\
\hline $\begin{array}{l}\text { Depression Anxiety Str } \\
\text { Stress }^{*}\end{array}$ & $\begin{array}{l}21 \\
14.81\end{array}$ & $13.80 \pm .83$ & $10.07 \pm 1.04$ \\
\hline
\end{tabular}

Note. Values are from the modified intention-to-treat Time 2 comparison analyses. ${ }^{*} p \leq .05$.

Table 3. Time 1 comparison points and Time 2 trimmed means and standard errors $\left(M_{\mathrm{t}} \pm S E\right)$ for measures analyzed via Yuen's tests in Study 2.

\begin{tabular}{cccc}
\hline & & Control & Experimental \\
\cline { 2 - 3 } Measure & Time 1 & Time $2\left(M_{\mathrm{t}} \pm S E\right)$ & Time $2\left(M_{\mathrm{t}} \pm S E\right)$ \\
\hline Five Facet Mindfulness Questionnaire-24 & & \\
Non-Judging & 13.00 & $13.50 \pm 1.08$ & $16.56 \pm .92$ \\
& 15.50 & $16.94 \pm .90$ & 17.6410 .67 \\
& 18.00 & $18.85 \pm .76$ & $18.00 \pm .73$ \\
\hline Depression Anxiety Stress Scales-21 & & \\
Depression & 2.00 & $3.50 \pm .78$ & $2.00 \pm .84$ \\
& 4.00 & $3.56 \pm .55$ & $2.40 \pm .74$ \\
Anxiety & 6.00 & $4.42 \pm .78$ & $3.00 \pm .97$ \\
& 2.00 & $2.74 \pm .75$ & $2.44 \pm .42$ \\
& 5.00 & $3.33 \pm .90$ & $3.23 \pm .67$ \\
& 8.00 & $6.20 \pm 1.79$ & $4.89 \pm 1.04$ \\
\hline
\end{tabular}

Note. Values are from the modified intention-to-treat Time 2 comparison analyses.

the PSS and the non-judging subscale of the FFMQ-24; $R^{2}=.09, F(1,44)=4.24, p=.05, B=$ .06 and $R^{2}=.17, F(1,43)=8.92, p=.005, B=.04$, respectively. In general, more time spent meditating was found to be associated with more negative change (i.e., greater decreases) in perceived stress and more positive change (i.e., larger increases) in non-judging over time. The removal of two outlier responses, corresponding to 105.00 and 180.00 minutes of meditation per week, rendered the relationship between meditation engagement and PSS scores non-significant, though the relationship between meditation engagement and non-judging remained significant; $R^{2}=.08, F(1,42)=3.72, p=.06, B=-.08$ and $R^{2}=.13, F(1,41)=6.10, p=.02, B=.05$, respectively. Following outlier removal, time spent meditating was also found to be a significant 
moderator of change in scores on the anxiety and stress subscales of the DASS- $21 ; R^{2}=.15, F(1$, $41)=7.05, p=.01, B=-.10$ and $R^{2}=.20, F(1,41)=10.27, p=.003, B=-.11$, respectively. Meditation engagement had a negative effect on the severity of both anxiety and stress, such that more meditation was associated with greater decreases in scores on each measure. Outlier removal did not have an effect on any of the other regressions (i.e., all remained non-significant). Visualizations of significant relationships are presented in Supplemental Digital Content 5.

\section{Per-Protocol}

Comparisons. Of the 64 participants who responded to both the T1 and T2 assessments, one in the experimental condition indicated that they did not meditate at all throughout the program. For PP T2 comparisons, therefore, $n=63\left(n_{\text {Experimental }}=24\right)$. PP comparisons deviated from mITT comparisons with respect to the non-reactivity and non-judging subscales of the FFMQ-24 and the depression subscale of the DASS-21 (see figures 5.5 and 5.6 in Supplemental Digital Content 5). All other results from PP comparisons were found to be comparable to the results from mITT comparisons.

Five Facet Mindfulness Questionnaire-24. Whereas mITT analyses found no T2 differences on the non-reactivity subscale of the FFMQ-24, PP analyses found that, after adjusting for differences in $\mathrm{T} 1$ scores $\left(M_{\mathrm{G}}=14.03\right)$, participants in the experimental condition $\left(M_{\text {adj }}=16.11, S E=.59\right)$ had significantly higher T2 scores than participants in the control condition $\left(M_{\mathrm{adj}}=14.60, S E=.47\right) ; F(1,60)=4.04, p=.05, \eta_{\mathrm{G}}^{2}=.06$. With respect to the nonjudging subscale, PP analyses employed different comparison points than mITT analyses: $\mathrm{T} 1=$ 11.00 (control, $M_{\mathrm{t}}=12.75, S E=1.19$; experimental, $\left.M_{\mathrm{t}}=15.89, S E=1.28\right), 15.00\left(\right.$ control, $M_{\mathrm{t}}=$ $16.67, S E=.79$; experimental, $\left.M_{\mathrm{t}}=17.33, S E=.80\right)$, and $19.00\left(\right.$ control, $M_{\mathrm{t}}=19.60, S E=.70$; experimental, $\left.M_{\mathrm{t}}=18.56, S E=.74\right)$. PP results were, however, similar to mITT results in that there were no differences in T2 non-judging scores at any of the T1 values considered (all $p>$ $.05)$.

Depression Anxiety Stress Scales-21. Unlike mITT analyses, PP analyses used a standard ANCOVA approach because depression subscale residuals were homoscedastic. Ultimately though, PP results were similar to mITT results in that T2 differences in scores on the depression subscale were not observed between conditions $\left(M_{\mathrm{G}}=8.83\right.$; control, $M_{\mathrm{adj}}=7.06, S E=$ .77 ; experimental, $\left.M_{\text {adj }}=4.78, S E=.98 ; p>.05\right)$.

Moderation. PP regression analyses included the 24 experimental participants from the PP comparison analyses and the 21 control participants who responded to both the T2 and T3 assessments (all 21 indicated that they meditated throughout the program). mITT analyses found that time spent meditating was a significant moderator of change in scores on the PSS when outlier values were included. In PP analyses, however, this relationship was not significant (see Figure 5.7 in Supplemental Digital Content 5); $R^{2}=.08, F(1,43)=3.82, p=.06, B=-.05$. All other results from PP analyses were found to be comparable to the results from mITT analyses.

\section{Discussion}

Participants were randomly assigned to either an experimental group, which took part in a 30-day mindfulness program, or a waitlist control condition, which began the 30-day program after the experimental group had completed it. Participants in the experimental condition experienced moderate post-intervention benefits to their self-reported well-being; at T2, they were found to have lower levels of negative affect and perceived stress and less severe symptoms associated with stress than participants in the control condition. Compared to the control group, experimental participants also displayed higher levels of positive affect and observing at T2. An effect of condition on T2 levels of non-reactivity was additionally noted, though this effect was 
only significant in PP analyses. All other T2 comparisons produced similar outcomes in both the mITT and PP analyses, implying that the Mindful Pause program is moderately effective in reducing stress, improving mood, and enhancing observation abilities, and that it has the potential to promote non-reactivity but adherence to the treatment protocol is necessary for this to occur.

Moderation analyses suggested that changes evoked by Mindful Pause may be influenced by the amount of time participants spend meditating throughout the program. In particular, program engagement was found to be negatively related to changes in perceived stress, although this relationship was only significant in mITT analyses prior to outlier removal. The nonsignificant nature of this relationship in analyses excluding outliers and non-meditators suggests that PSS changes as a function of time spent meditating are only apparent when zero or extreme amounts of meditation are taken into account; among moderately active participants, changes in perceived stress are unlikely to be related to program engagement. In contrast, degree of engagement does seem to be reasonably predictive of change in non-judging, as time spent meditating was found to be positively related to change on the non-judging subscale of the FFMQ-24 in both mITT and PP analyses both with and without outliers. This finding is consistent with suggestions by Baer and colleagues ${ }^{81,89}$ that the ability to observe experiences and sensations without judgment develops gradually over time. Greater engagement was also found to predict greater decreases in the severity of symptoms associated with stress and anxiety but only after outlier removal, implying that there is an amount of meditation beyond which further meditation-induced improvements in symptomatology are unlikely.

Between T1 and T2, attrition was found to be related to both age and condition, with younger participants and participants in the experimental condition being less likely to respond to the T2 assessment than those who were older or in the control condition. The effect of age on participation is puzzling because the age difference between responders and non-responders was fairly small and attrition was unrelated to other factors that one might expect to be related to age (e.g., job position, length of time spent working in one's current position, and number of hours spent working per week). Participants in this study were, however, predominately female and previous research involving women has found a negative relationship between attrition and age, ${ }^{90}$ so this finding may not be entirely unique. The effect of condition on attrition, in contrast, is more readily understandable as participants likely experienced a decrease in interest and/or perceived obligation towards study participation upon completion of the intervention; this would explain the low rates of responding at T2 among experimental participants (and at T3 among waitlist control participants).

\section{General Discussion}

We carried out two studies of two closely related online mindfulness interventions. Each program was found to have moderate but reliable benefits to participants. In Study 1, legal professionals participated in the Anxious Lawyer program - an 8-week intervention consisting of readings, informal mindfulness activities, and online meditations. At the end of the program, participants reported significant increases in positive affect, psychological resilience, and aspects of trait mindfulness (i.e., non-judging, observing, awareness, describing, and non-reactivity), as well as decreases in perceived stress; negative affect; and the severity of symptoms associated with depression, anxiety, and stress. In Study 2, lawyers participated in a 30-day intervention called Mindful Pause, which is comprised of daily emails and short, online, guided meditations. Compared to a waitlist control group, experimental participants displayed lower T2 levels of perceived stress and negative affect; less severe symptoms of stress; higher levels of positive 
affect and observing; and, for those who actively meditated during the program, greater nonreactivity. To summarize, the Anxious Lawyer program was found to be associated with changes on all of the measures considered and all outcomes were replicated across mITT and PP analyses; the Mindful Pause program largely impacted stress and mood and enhanced two of the five aspects of trait mindfulness.

\section{Contrasts and Comparisons}

As in all studies, outcome discrepancies between the two programs are undoubtedly related to population differences to some extent. For example, individuals may have been more internally motivated to participate in Study 1 than Study 2 given that it was a more casual evaluation of a program arranged by an extracurricular club, as opposed to a more structured examination of an intervention offered on the job. Results may also have been affected by differences in the pre-intervention states of participants and/or stressors inherent to the work of each group at the time in which the studies were conducted. Discrepancies may additionally be attributed to variations in the length and content of each of the interventions and the analytic strategies employed in each study.

\section{Intervention Lengths}

Mindfulness has been proposed to act via a combination of mechanisms. ${ }^{44}$ Like many other skills, however, mindfulness is cultivated gradually. ${ }^{91}$ For those just beginning a mindfulness meditation practice, perhaps one of the first mechanisms to be initiated is relaxation, which research suggests can be invoked neurophysiologically by simple meditation techniques. ${ }^{92}$ Cognitive reappraisal, enduring changes to emotional reactivity, and sweeping alterations to an individual's level of trait mindfulness, on the other hand, presumably take longer to evolve as one's mindfulness abilities develop over time. As a result, programs like Mindful Pause are likely restricted in the scope of outcomes that they are capable of promoting due to their limited durations. This may explain why the 8-week Anxious Lawyer program was found to be associated with improvements on all of the measures considered while Mindful Pause - a 30-day program of shorter meditations - seems to have impacted factors that might benefit from enhanced awareness and relaxation (e.g., reductions in stress and improvements in mood).

\section{Intervention Content}

Though the interventions varied widely with respect to content, two major points of distinction are the inclusion or exclusion of (1) didactic material and (2) suggestions for off-themat mindfulness activities. Both of these features were included in the Anxious Lawyer program, which involved guided meditations, informal mindfulness activities, and a book that presents both general explanations of topics related to mindfulness and specific examples of how mindfulness can be applied within the context of the legal profession. Its apparent ability to produce improvements in a variety of areas is likely related to its detailed text, which provides a thorough introduction to the topic of mindfulness, and its use of population-directed examples and informal exercises, both of which encourage participants to adopt a mindful approach to living that extends beyond meditation. Mindful Pause, in comparison, was almost solely meditation-based and included relatively less material designed to educate participants on mindfulness and few informal mindfulness activities. Mindful Pause, therefore, may be more appropriately described as meditation-based than mindfulness-based. Differences in intervention content provide a likely explanation for why the magnitude of some Mindful Pause-related changes were found to be dependent on meditation engagement while Anxious Lawyer-related changes were not. Meditation engagement may not have been an adequate proxy for Anxious Lawyer program engagement; had a more comprehensive measure involving pages read and 
informal activity completion been used, significant predictive relationships may have been found.

As meditation has long been linked to relaxation and stress reduction, ${ }^{93,94}$ it is unsurprising that Mindful Pause was found to decrease stress and improve mood. Without accompanying didactic material and suggestions for informal mindfulness applications, however, Mindful Pause seems to have been incapable of bringing about changes in other areas, such as resilience and depression and anxiety severity. Mindful Pause also failed to evoke changes in all areas of trait mindfulness, perhaps because it was limited in its capacity to encourage the development of certain mindfulness skills. For instance, whereas mindfulness-focused meditations may emphasize observing and non-reactivity - the two skills that were found to be enhanced by Mindful Pause - informal mindfulness activities would likely be particularly helpful for fostering an ability to act with awareness; this conclusion is broadly supported by research suggesting that, of the five aspects of trait mindfulness measured by the FFMQ, awareness and describing are the least correlated with meditation experience, ${ }^{9}$ implying that meditation alone is not always sufficient for evoking changes in areas such as these.

\section{Analytic Strategies}

The Anxious Lawyer program seems to have been the most effective of the two interventions as it produced the broadest and most consistent range of results. One might feel justified in making this assumption because the Anxious Lawyer program was longer and more comprehensive than Mindful Pause. Though this conclusion may well be true, however, Study 1 relied solely on within-group comparisons and did not include a control condition. Consequently, although participants in this study seem to have improved over time, changes cannot be ascribed to the Anxious Lawyer program definitively. Study 2, on the other hand, included a control group and implemented between-group comparisons to better isolate the effects that could be attributed to Mindful Pause; that this study was characterized by less significance than Study 1 is, therefore, unsurprising since it employed a relatively stronger experimental design and more stringent forms of statistical tests.

\section{Limitations and Future Directions}

The lack of a control group is a clear limitation of Study 1 which necessitates that results associated with the Anxious Lawyer program be interpreted with caution. Outcomes in Study 2 can be more readily ascribed to Mindful Pause due to the use of random assignment and the inclusion of a waitlist control group in this study. A stronger and more interesting design would have also involved an active control condition. Contrasting each intervention with an alternative task, such as reading or relaxation training, would elucidate whether outcomes were due to mindfulness or mere relaxation - a common by-product of meditation, ${ }^{92-94}$ which was a primary feature of both programs.

In using both mITT and PP analyses, this paper sought to provide a more accurate assessment of the external validity of the interventions. Whereas PP analyses highlight the maximal efficacy of an intervention, intention-to-treat analyses are more representative of the outcomes that can be realistically expected with program administration. ${ }^{95}$ By including all participants, intention-to-treat approaches also maintain random assignment and mitigate some of the bias that can be introduced when selecting subsets of participants for PP analyses. This paper, however, employed a mITT approach, whereby non-compliant participants were included in analyses but missing data was not imputed. Demographic assessments of the participants included in between-group comparisons in Study 2 found no systematic differences between conditions, implying that random assignment was maintained in these sub-samples to some 
extent. Nevertheless, it would be incorrect to state that the mITT analyses in this paper provide a complete and authentic estimate of the external validity of the interventions, especially since most of the samples included in mITT analyses differed from the samples in PP analyses by only a few participants. Instead, results should be interpreted as a suggestion of the changes that each intervention is capable of inducing. Future studies should examine both the Anxious Lawyer program and Mindful Pause using a more stringent intention-to-treat approach; in the meantime, organizations who are interested in administering these interventions should be aware that outcomes may differ from those reported here.

The primary reason for using a mITT approach was that imputation of missing data would have resulted in a large amount of estimation due to the high rates of participant attrition observed in each study. Reported rates of study attrition are likely inflated compared to program attrition as participants were not required to respond to the assessments in order to participate in the interventions. Though not ideal, this design was unavoidable due to the convenience-based recruitment strategies employed in each study (and was, to some degree, beneficial as the separation of program implementation and assessment minimizes the potential for conflicts of interest).

The rates of attrition observed in these studies are broadly consistent with what has been observed in other studies of online ${ }^{96}$ and mindfulness-based ${ }^{7,97-99}$ interventions. Both study and program attrition, however, was likely amplified by the use of web-based modalities. Online mediums may be seen as offering less support or engagement than an in-person course, leading participants to feel less enthusiasm or accountability towards completing them. ${ }^{100}$ Compared to in-class programs, however, internet-based approaches tend to be less costly to administer. ${ }^{101}$ Online programs can also be easier to integrate into a busy work day because they require less large-scale organization and are typically less time consuming to participate in. ${ }^{100}$ Of course, busy professionals may find it difficult to prioritize a personal mindfulness practice in the face of important work-related tasks. Consequently, future studies involving online methodology should consider ways to encourage regular participation. For example, online message boards or instant messaging platforms may help to facilitate a feeling of community and obligation. Forgetfulness, on the other hand, could be mitigated via digital calendars programmed with daily, self-identified practice times coupled with email or app-based notifications.

Aside from increased rates of attrition, online platforms present challenges with respect to the types of data that can be collected. The studies in this paper, for instance, relied solely on self-report data and, though it is clearly valuable to know whether an individual feels subjectively more positive or less stressed, self-reports are susceptible to response bias and demand characteristics. Self-selection may also have occurred as participants were informed that each study was related to mindfulness. Issues of bias and self-selection limit the generalizability of results because individuals with an interest in mindfulness may have been over-sampled and participants who possessed an expectation that mindfulness would improve their well-being may have adjusted their responses - consciously or not - to reflect their beliefs.

Beliefs and expectations likely play an important role in the outcomes achieved through mindfulness. In fact, expectation of relief and enhancement of the placebo effect is listed as a key element of mindfulness-based stress reduction (MBSR) ${ }^{102}$ - one of the most well-known mindfulness-based interventions. It may, therefore, be important for future research to employ measures like the Meditation Intentions Questionnaire ${ }^{103}$ so that participant expectations can be taken into consideration when assessing outcomes. Researchers looking to minimize potential sources of error and to isolate mindfulness-specific effects may, however, also wish to consider 
forms of measurement that do not rely on self-report, such as external ratings, heart rate variability, and cortisol levels; neurophysiological techniques, in particular, will be especially important for helping to clarify the neurological underpinnings of mindfulness practice.

\section{Conclusion}

Mindfulness has been linked to a plethora of positive outcomes, ${ }^{2,12}$ many of which could be beneficial for lawyers. Enhanced concentration and emotion regulation, for instance, could facilitate more effective negotiating and the development of healthy relationships with clientsespecially those burdened with unwieldy emotional baggage or who are otherwise difficult to deal with. ${ }^{68,76,104}$ Mindfulness has also been proposed as an effective tool for managing many conditions and symptoms that are reported to be prevalent in the legal community, such as depression and stress. ${ }^{26,105}$ Adding to this literature, this paper suggests that mindfulness training is effective for improving health and wellness among legal professionals and even the simple act of brief, daily meditation seems to have the potential to reduce stress and boost mood. For those looking to enhance well-being, improve clarity and attention, or simply gain a greater awareness and understanding of the self, therefore, mindfulness may be worthy of exploration. 


\section{References}

1. Bishop SR, Lau M, Shapiro S, et al. Mindfulness: a proposed operational definition. Clin Psychol - Sci Pr. 2004; 11:230-241.

2. Brown KW, Ryan RM, Creswell JD. Mindfulness: theoretical foundations and evidence for its salutary effects. Psychol Inq. 2007; 18:211-237.

3. Kabat-Zinn J. Wherever you go there you are: mindfulness meditation in everyday life (10th anniversary ed.). New York: Hyperion; 2005.

4. Jamieson SD, Tuckey MR. Mindfulness interventions in the workplace: a critique of the current state of the literature. J Occup Health Psych. 2017; 22:180-193.

5. Brown KW, Ryan RM. The benefits of being present: mindfulness and its role in psychological well-being. J Pers Soc Psychol. 2003; 84:822-848.

6. Klatt MD, Buckworth J, Malarkey WB. Effects of low-dose mindfulness-based stress reduction (MBSR-ld) on working adults. Health Educ Behav. 2009; 36:601-614.

7. Nadler R, Carswell J, Minda JP. Online mindfulness training increases well-being, emotional intelligence, and workplace competency ratings: a randomized waitlist-controlled trial. Front Psychol. 2020; 11:255.

8. Roeser RW, Schonert-Reichl KA, Jha A, et al. Mindfulness training and reductions in teacher stress and burnout: results from two randomized, waitlist-control field trials. J Educ Psychol. 2013; 105:787-804.

9. Baer RA, Smith GT, Lykins E, et al. Construct validity of the five facet mindfulness questionnaire in meditating and nonmeditating samples. Assessment. 2008; 15:329-342.

10. Shapiro SL, Brown KW, Thoresen C, Plante TG. The moderation of mindfulness-based stress reduction effects by trait mindfulness: results from a randomized controlled trial. J Clin Psychol. 2011; 67:267-277.

11. Goleman DJ, Schwartz GE. Meditation as an intervention in stress reactivity. J Consult Clin Psych. 1976; 44:456-466.

12. Creswell JD. Mindfulness interventions. Annu Rev Psychol. 2017; 68:491-516.

13. Cherkin DC, Sherman KJ, Balderson BH, et al. Effect of mindfulness-based stress reduction vs cognitive behavioral therapy or usual care on back pain and functional limitations in adults with chronic low back pain: a randomized clinical trial. JAMA. 2016; 315:1240-1249.

14. Garland EL, Manusov EG, Froeliger B, Kelly A, Williams JM, Howard MO. Mindfulnessoriented recovery enhancement for chronic pain and prescription opioid misuse: results from an early-stage randomized controlled trial. J Consult Clin Psych. 2014; 82:448-459.

15. Morone NE, Greco CM, Moore CG, et al. A mind-body program for older adults with chronic low back pain: a randomized clinical trial. JAMA Intern Med. 2016; 176:329-337.

16. Banks K, Newman E, Saleem J. An overview of the research on mindfulness-based interventions for treating symptoms of posttraumatic stress disorder: a systematic review. J Clin Psychol. 2015; 71:935-963.

17. Creswell JD, Myers HF, Cole SW, Irwin MR. Mindfulness meditation training effects on CD4+ T lymphocytes in HIV-1 infected adults: a small randomized controlled trial. Brain Behav Immun. 2009; 23:184-188.

18. Gaylord SA, Palsson OS, Garland EL, et al. Mindfulness training reduces the severity of irritable bowel syndrome in women: results of a randomized controlled trial. Am J Gastroenterol. 2011; 106:1678-1688. 
19. Gonzalez-Garcia M, Ferrer MJ, Borras X, et al. Effectiveness of mindfulness-based cognitive therapy on the quality of life, emotional status, and CD4 cell count of patients aging with HIV infection. AIDS Behav. 2014; 18:676-685.

20. Kabat-Zinn J, Wheeler E, Light T, et al. Influence of a mindfulness meditation-based stress reduction intervention on rates of skin clearing in patients with moderate to severe psoriasis undergoing photo therapy (UVB) and photochemotherapy (PUVA). Psychosom Med. 1998; 60:625-632.

21. Ong JC, Manber R, Segal Z, Xia Y, Shapiro S, Wyatt JK. A randomized controlled trial of mindfulness meditation for chronic insomnia. Sleep. 2014; 37:1553-1563.

22. Polusny MA, Erbes CR, Thuras P, et al. Mindfulness-based stress reduction for posttraumatic stress disorder among veterans: a randomized clinical trial. JAMA. 2015; 314:456-465.

23. SeyedAlinaghi S, Jam S, Foroughi M, et al. RCT of mindfulness-based stress reduction delivered to HIV+ patients in Iran: effects on CD4+ T lymphocyte count and medical and psychological symptoms. Psychosom Med. 2012; 74:620-627.

24. Goldin PR, Gross JJ. Effects of mindfulness-based stress reduction (MBSR) on emotion regulation in social anxiety disorder. Emotion. 2010; 10:83-91.

25. Hoge EA, Bui E, Marques L, et al. Randomized controlled trial of mindfulness meditation for generalized anxiety disorder: effects on anxiety and stress reactivity. J Clin Psychiat. 2013; 74:786-792.

26. Chiesa A, Serretti A. Mindfulness-based stress reduction for stress management in healthy people: a review and meta-analysis. J Altern Complem Med. 2009; 15:593-600.

27. Khoury B, Sharma M, Rush SE, Fournier C. Mindfulness-based stress reduction for healthy individuals: a meta-analysis. J Psychosom Res. 2015; 78:519-528.

28. Sharma M, Rush SE. Mindfulness-based stress reduction as a stress management intervention for healthy individuals: a systematic review. J Evid-Based Compl Alt Med. 2014; 19:271-286. 29. Bowen S, Witkiewitz K, Clifasefi SL, et al. Relative efficacy of mindfulness-based relapse prevention, standard relapse prevention, and treatment as usual for substance use disorders: a randomized clinical trial. JAMA Psychiat. 2014; 71:547-556.

30. Kuyken W, Byford S, Taylor RS, et al. Mindfulness-based cognitive therapy to prevent relapse in recurrent depression. J Consult Clin Psych. 2008; 76:966-978.

31. Ma SH, Teasdale JD. Mindfulness-based cognitive therapy for depression: replication and exploration of differential relapse prevention effects. J Consult Clin Psych. 2004; 72:31-40. 32. Piet J, Hougaard E. The effect of mindfulness-based cognitive therapy for prevention of relapse in recurrent major depressive disorder: a systematic review and meta-analysis. Clin Psychol Rev. 2011; 31:1032-1040.

33. Segal ZV, Bieling P, Young T, et al. Antidepressant monotherapy vs sequential pharmacotherapy and mindfulness-based cognitive therapy, or placebo, for relapse prophylaxis in recurrent depression. Arch Gen Psychiat. 2010; 67:1256-1264.

34. Teasdale JD, Segal ZV, Williams JM, Ridgeway VA, Soulsby JM, Lau MA. Prevention of relapse/recurrence in major depression by mindfulness-based cognitive therapy. J Consult Clin Psych. 2000; 68:615-623.

35. Jensen CG, Vangkilde S, Frokjaer V, Hasselbalch SG. Mindfulness training affects attention — or is it attentional effort? J Exp Psychol Gen. 2012; 141:106-123.

36. Jha AP, Krompinger J, Baime MJ. Mindfulness training modifies subsystems of attention. Cogn Affect Behav Ne. 2007; 7:109-119. 
37. Mrazek MD, Smallwood J, Schooler JW. Mindfulness and mind-wandering: finding convergence through opposing constructs. Emotion. 2012; 12:442-448.

38. Tang Y-Y, Ma Y, Wang J, et al. Short-term meditation training improves attention and selfregulation. P Natl Acad Sci USA. 2007; 104:17152-17156.

39. Zeidan F, Johnson SK, Diamond BJ, David Z, Goolkasian P. Mindfulness meditation improves cognition: evidence of brief mental training. Conscious Cogn. 2010; 19:597-605.

40. Hafenbrack AC, Kinias Z, Barsade SG. Debiasing the mind through meditation: mindfulness and the sunk-cost bias. Psychol Sci. 2014; 25:369-376.

41. Kiken LG, Shook NJ. Looking up: mindfulness increases positive judgments and reduces negativity bias. Soc Psychol Pers Sci. 2011; 2:425-431.

42. Lueke A, Gibson B. Mindfulness meditation reduces implicit age and race bias: the role of reduced automaticity of responding. Soc Psychol Pers Sci. 2014; 6:284-291.

43. Lykins ELB, Baer RA. Psychological functioning in a sample of long-term practitioners of mindfulness meditation. J Cogn Psychot. 2009; 23:226-241.

44. Baer RA. Mindfulness training as a clinical intervention: a conceptual and empirical review. Clin Psychol-Sci Pr. 2006; 10:125-143.

45. Shapiro SL, Carlson LE, Astin JA, Freedman B. Mechanisms of mindfulness. J Clin Psychol. 2006; 62:373-386.

46. Agnew H. 'Mindfulness' gives stressed-out bankers something to think about. Financ Times [online]. May 4, 2014. Available at: https:/www.ft.com/content/331b85d0-d20d-11e3-8b5b00144feabdc0. Accessed February 8, 2020.

47. Confino J. Google's head of mindfulness: 'goodness is good for business.' Guard [online]. May 14, 2014. Available at: http://www.theguardian.com/sustainable-business/googlemeditation-mindfulness-technology. Accessed February 8, 2020.

48. Gelles D. The mind business. Financ Times [online]. August 24, 2012. Available at: https:/www.ft.com/content/d9cb7940-ebea-11e1-985a-00144feab49a. Accessed February 8, 2020.

49. Gelles D. At Aetna, a C.E.O.'s management by mantra. N Y Times [online]. February 27, 2015. Available at: https://www.nytimes.com/2015/03/01/business/at-aetna-a-ceos-managementby-mantra.html. Acccessed February 8, 2020.

50. Lomas T, Medina JC, Ivtzan I, Rupprecht S, Hart R, Eiroa-Orosa FJ. The impact of mindfulness on well-being and performance in the workplace: an inclusive systematic review of the empirical literature. Eur J Work Organ Psy. 2017; 26:492-513.

51. Aikens KA, Astin J, Pelletier KR, et al. Mindfulness goes to work: impact of an online workplace intervention. J Occup Environ Med. 2014; 56:721-731.

52. Frank JL, Reibel D, Broderick P, Cantrell T, Metz S. The effectiveness of mindfulness-based stress reduction on educator stress and well-being: results from a pilot study. Mindfulness. 2015; 6:208-216.

53. Krusche A, Jack CD, Blunt C, Hsu A. Mindfulness-based organisational education: an evaluation of a mindfulness course delivered to employees at the Royal Orthopaedic Hospital. Mindfulness. 2020; 11:362-373.

54. Wolever RQ, Bobinet KJ, McCabe K, et al. Effective and viable mind-body stress reduction in the workplace: a randomized controlled trial. J Occup Health Psych. 2012; 17:246-258.

55. Shapiro SL, Astin JA, Bishop SR, Cordova M. Mindfulness-based stress reduction for health care professionals: results from a randomized trial. Int J Stress Manage. 2005; 12:164 -176. 
56. Hülsheger UR, Alberts HJEM, Feinholdt A, Lang JWB. Benefits of mindfulness at work: the role of mindfulness in emotion regulation, emotional exhaustion, and job satisfaction. J Appl Psychol. 2013; 98:310-325.

57. Krasner MS, Epstein RM, Beckman H, et al. Association of an educational program in mindful communication with burnout, empathy, and attitudes among primary care physicians. JAMA. 2009; 302:1284-1293.

58. Jha AP, Morrison AB, Dainer-Best J, Parker S, Rostrup N, Stanley EA. Minds “at attention": mindfulness training curbs attentional lapses in military cohorts. PloS One. 2015; 10:e0116889. 59. Slutsky J, Chin B, Raye J, Creswell JD. Mindfulness training improves employee well-being: a randomized controlled trial. J Occup Health Psych. 2019; 24:139-149.

60. Benjamin GAH, Kaszniak A, Sales B, Shanfield SB. The role of legal education in producing psychological distress among law students and lawyers. Am Bar Found Res J. 1986; 11:225-252. 61. Boyd JH, Weissman MM. Epidemiology of affective disorders: a reexamination and future directions. Arch Gen Psychiat. 1981; 38:1039-1046.

62. Benjamin GAH, Darling EJ, Sales B. The prevalence of depression, alcohol abuse, and cocaine abuse among United States lawyers. Int J Law Psychiat. 1990; 13:233-246.

63. Organ JM, Jaffe DB, Bender KM. Suffering in silence: the survey of law student well-being and the reluctance of law students to seek help for substance use and mental health concerns. J Legal Educ. 2016; 66:116-156.

64. Krill PR, Johnson R, Albert L. The prevalence of substance use and other mental health concerns among American attorneys. J Addict Med. 2016; 10:46-52.

65. Oreskovich MR, Kaups KL, Balch CM, et al. Prevalence of alcohol use disorders among American surgeons. AMA Arch Surg. 2012; 147:168-174.

66. Doraisamy J. The wellness doctrines: for law students \& young lawyers. Sydney: Xoum Publishing; 2015.

67. Boyce B. The law of mindfulness. Mindful [online]. August 26, 2010. Available at: https://www.mindful.org/the-law-of-mindfulness/. Accessed June 6, 2019.

68. Riskin LL. The contemplative lawyer: on the potential contributions of mindfulness meditation to law students, lawyers, and their clients. Harv Negot Law Rev. 2002; 7:1-66. 69. The proceedings of the mindful lawyer conference. [web site]. 2010. Available at: http://www.mindfullawyerconference.org/. Accessed June 6, 2019.

70. Leizerman M, Rinsen Weik J. The zen lawyer: winning with mindfulness. Portland: Trial Guides LLC; 2018.

71. Martin N. Lawyering from the inside out: learning professional development through mindfulness and emotional intelligence. New York: Cambridge University Press; 2018.

72. Scott C. Mindfulness in law: a path to well-being and balance for lawyers and law students. Ariz Law Rev. 2018; 60:635-674.

73. The National Task Force on Lawyer Well-Being. The path to lawyer well-being: practical recommendations for positive change [web site]. August 14, 2017. Available at:

https://www.americanbar.org/content/dam/aba/images/abanews/ThePathToLawyerWellBeingRe portRevFINAL.pdf. Accessed June 6, 2019.

74. American Bar Association. Wellness, mindfulness, work-life balance [web site]. May 9, 2019. Available at:

https://www.americanbar.org/groups/lawyer_assistance/resources/lawyer_wellness/. Accessed June 6, 2019. 
75. Spijkerman MPJ, Pots WTM, Bohlmeijer ET. Effectiveness of online mindfulness-based interventions in improving mental health: a review and meta-analysis of randomised controlled trials. Clin Psychol Rev. 2016; 45:102-114.

76. Cho J, Gifford K. The anxious lawyer: an 8-week guide to a joyful and satisfying law practice through mindfulness and meditation. Chicago: ABA Publishing; 2016.

77. Qualtrics [computer program]. Version 2016-2019. Provo: Qualtrics; 2005.

78. Cohen S, Kamarck T, Mermelstein R. A global measure of perceived stress. J Health Soc Behav. 1983; 24:385-396.

79. Watson D, Clark LA, Tellegen A. Development and validation of brief measures of positive and negative affect: the PANAS scales. J Pers Soc Psychol. 1988; 54:1063-1070.

80. Smith BW, Dalen J, Wiggins K, Tooley E, Christopher P, Bernard J. The Brief Resilience Scale: assessing the ability to bounce back. Int J Behav Med. 2008; 15:194-200.

81. Baer RA, Smith GT, Hopkins J, Krietemeyer J, Toney L. Using self-report assessment methods to explore facets of mindfulness. Assessment. 2006; 13:27-45.

82. Bohlmeijer E, ten Klooster PM, Fledderus M, Veehof M, Baer R. Psychometric properties of the five facet mindfulness questionnaire in depressed adults and development of a short form. Assessment. 2011; 18:308-320.

83. Lovibond SH, Lovibond PF. Manual for the depression anxiety stress scales (DASS) (version 2). Sydney: Psychology Foundation of Australia; 1995.

84. R: a language and environment for statistical computing [computer program]. Version 3.6.3. R Core Team; 2020.

85. McHugh ML. The chi-square test of independence. Biochem Medica. 2013; 23:143-149.

86. Judd CM, Kenny DA, McClelland GH. Estimating and testing mediation and moderation in within-subject designs. Psychol Methods. 2001; 6:115-134.

87. Van Breukelen GJP. ANCOVA versus change from baseline: more power in randomized studies, more bias in nonrandomized studies [corrected]. J Clin Epidemiol. 2006; 59:920-925. 88. Mair P, Wilcox R. Robust statistical methods in R using the WRS2 package. Behav Res Methods. 2020; 52:464-488.

89. Baer RA, Smith GT, Allen KB. Assessment of mindfulness by self-report: The Kentucky Inventory of Mindfulness Skills. Assessment. 2004; 11:191-206.

90. Young AF, Powers JR, Bell SL. Attrition in longitudinal studies: who do you lose? Aust NZ J Publ Heal. 2006; 30:353-361.

91. Gunaratana H. Mindfulness in plain English (20th anniversary ed.). Boston: Wisdom Publications; 2011.

92. Lazar SW, Bush G, Gollub RL, Fricchione GL, Khalsa G, Benson H. Functional brain mapping of the relaxation response and meditation. Neuroreport. 2000; 11:1581-1585.

93. Benson H, Klipper MZ. The relaxation response. New York: William Morrow and Company, Inc; 1975.

94. Morse DR, Martin JS, Furst ML, Dubin LL. A physiological and subjective evaluation of meditation, hypnosis, and relaxation. Psychosom Med. 1977; 39:304-324.

95. Ranganathan P, Pramesh CS, Aggarwal R. Common pitfalls in statistical analysis: intentionto-treat versus per-protocol analysis. Perspect Clin Res. 2016; 7:144-146.

96. Christensen H, Griffiths KM, Farrer L. Adherence in internet interventions for anxiety and depression. J Med Internet Res. 2009; 11:e13.

97. Cavanagh K, Strauss C, Cicconi F, Griffiths N, Wyper A, Jones F. A randomised controlled trial of a brief online mindfulness-based intervention. Behav Res Ther. 2013; 51:573-578. 
98. Economides M, Martman J, Bell MJ, Sanderson B. Improvements in stress, affect, and irritability following brief use of a mindfulness-based smartphone app: a randomized controlled trial. Mindfulness. 2018; 9:1584-1593.

99. Howells A, Ivtzan I, Eiroa-Orosa FJ. Putting the 'app' in happiness: a randomised controlled trial of a smartphone-based mindfulness intervention to enhance wellbeing. J Happiness Stud. 2016; 17:163-185.

100. Andersson G, Titov N. Advantages and limitations of internet-based interventions for common mental disorders. World Psychiatry. 2014; 13:4-11.

101. Hedman E, Andersson E, Ljótsson B, Andersson G, Rück C, Lindefors N. Costeffectiveness of internet-based cognitive behavior therapy vs. cognitive behavioral group therapy for social anxiety disorder: results from a randomized controlled trial. Behav Res Ther. 2011; 49:729-736.

102. Kabat-Zinn J. An outpatient program in behavioral medicine for chronic pain patients based on the practice of mindfulness meditation: theoretical considerations and preliminary results. Gen Hosp Psychiat. 1982; 4:33-47.

103. Kharlas D. The development and validation of a preliminary meditation intentions questionnaire [online master's thesis]. London (CAN): Western University; 2018. Available at: https://ir.lib.uwo.ca/etd/5832/. Accessed April 30, 2020.

104. Riskin LL. Annual Saltman lecture: further beyond reason: emotions, the core concerns, and mindfulness in negotiation. Nev Law J. 2009; 10:289-337.

105. Hofmann SG, Sawyer AT, Witt AA, Oh D. The effect of mindfulness-based therapy on anxiety and depression: a meta-analytic review. J Consult Clin Psych. 2010; 78:169-183.

106. Nielsen EG. Moving beyond the mat: exploring the application of mindfulness training in professional and educational settings [online doctoral dissertation]. London (CAN): Western University, 2020. Available at: https://ir.lib.uwo.ca/etd/7350/. 


\section{Footnotes}

1. Both studies were conducted as part of the first author's doctoral dissertation project. ${ }^{106}$

2. Study participation was not required for participation in either program discussed in this paper. In both studies, the interventions were administered by the program developers. The program developers, however, played no role in study design, implementation, data collection, analysis, or manuscript preparation. The authors of this paper are not, in any way, affiliated with the Anxious Lawyer or Mindful Pause programs and declare no conflicts of interest.

3. Participants in both studies were also asked to complete a measure of perceived workplace effectiveness referred to as the Job Effectiveness Questionnaire (JEQ). Because this measure has not been validated, however, associated analyses are presented in Supplemental Digital Content 2, rather than in the text.

4. It is, of course, possible that participants participated in the program without responding to the assessments. For the purpose of discussion, however, it has been assumed that those who failed to respond to the assessments also failed to complete the program. 
Supplementary Information 1: The Anxious Lawyer Program

The Anxious Lawyer (Cho \& Gifford, 2016) was written by two individuals who have experience with both mindfulness and the legal profession. Cho, who is a partner at JC Law Group PC, has attended numerous mindfulness retreats and completed several courses in mindfulness, including the teacher training practicum for Kabat-Zinn's (1982) MBSR program. Gifford - a former attorney for the Federal Reserve Bank of New York - has practiced yogabased meditation for 15 years and teaches mindfulness as an executive coach. In their book, Cho and Gifford provide an accessible introduction to mindfulness and practical examples of how mindfulness can be applied in various situations that are common in the practice of law (e.g., dealing with difficult clients, negotiating with opposing counsel, etc.). The book also outlines an 8-week program (detailed in Table 1.1) that pairs specific readings with both formal and informal mindfulness practices. Formal practices include guided meditations, which are presented in written form in the text and are also available in audio form narrated by the authors of the book at www.theanxiouslawyer.com. Informal practices encourage contemplation and suggest ways in which mindfulness can be incorporated into the activities of everyday life. Readers are encouraged to track their experiences with the various practices each week by completing meditation logs. The logs, which provide space to record the time and length spent practicing each day and notes regarding both the formal and informal activities, are included at the end of each chapter. 
Table 1.1. Summary of the 8-week mindfulness program outlined in The Anxious Lawyer (Cho \& Gifford, 2016) and assessed in Study 1.

\begin{tabular}{|c|c|c|c|}
\hline Week & Topic/Chapter & Formal Practice & Informal Practice \\
\hline 1 & $\begin{array}{l}\text { Beginning to } \\
\text { Meditate }\end{array}$ & $\begin{array}{l}\text { Body Scan: one 6-min meditation } \\
\text { and one } 24 \text {-min meditation, each } \\
\text { focusing on the sensations felt in } \\
\text { different parts of the body }\end{array}$ & $\begin{array}{l}\text { Mindful Showering: focus on } \\
\text { the physical sensations } \\
\text { experienced when showering }\end{array}$ \\
\hline 2 & Mindfulness & $\begin{array}{l}\text { Breathing Focused: one 12-min } \\
\text { meditation focusing on the } \\
\text { sensations of breathing }\end{array}$ & $\begin{array}{l}\text { Mindfulness in Daily Life: } \\
\text { brainstorm five activities that } \\
\text { can be performed mindfully } \\
\text { and select one to practice }\end{array}$ \\
\hline 3 & Clarity & $\begin{array}{l}\text { Following Your Thoughts: one 12- } \\
\text { min meditation focusing on the } \\
\text { quality (i.e., speed, progression, } \\
\text { volume and tone, as opposed to } \\
\text { content) of one's thoughts }\end{array}$ & $\begin{array}{l}\text { Transitional Moments: practice } \\
\text { grounding oneself in the } \\
\text { present moment during times } \\
\text { of transition between activities }\end{array}$ \\
\hline 4 & $\begin{array}{l}\text { Compassion } \\
\text { Toward } \\
\text { Others }\end{array}$ & $\begin{array}{l}\text { Compassion Toward Others: one } \\
\text { 12-min meditation focusing on } \\
\text { cultivating feelings of compassion } \\
\text { for others }\end{array}$ & $\begin{array}{l}\text { Sending Good Wishes to } \\
\text { Others: practice sending silent } \\
\text { good wishes to strangers } \\
\text { encountered throughout the day }\end{array}$ \\
\hline 5 & $\begin{array}{c}\text { Self- } \\
\text { Compassion }\end{array}$ & $\begin{array}{l}\text { Self-Compassion: one } 12 \text {-min } \\
\text { meditation focusing on cultivating } \\
\text { feelings of compassion for the self }\end{array}$ & $\begin{array}{l}\text { Being Kind to Oneself: ask the } \\
\text { question "How can I be kind to } \\
\text { myself?" and notice the } \\
\text { resulting thoughts and feelings }\end{array}$ \\
\hline 6 & $\begin{array}{l}\text { Mantra } \\
\text { Repetition }\end{array}$ & $\begin{array}{l}\text { Mantra: two 6-min meditations } \\
\text { involving the repetition of a mantra } \\
\text { (i.e., a word or phrase designed to } \\
\text { provide affirmation or motivation } \\
\text { and/or aid in concentration) }\end{array}$ & $\begin{array}{l}\text { Mantra Repetition: incorporate } \\
\text { silent mantra repetition into } \\
\text { other activities (e.g., while } \\
\text { taking public transit) }\end{array}$ \\
\hline 7 & Heartfulness & $\begin{array}{l}\text { Heart-Centered: two 6-min } \\
\text { meditations focusing on the heart }\end{array}$ & $\begin{array}{l}\text { A Higher Goal: identify a } \\
\text { personal ideal or goal and offer } \\
\text { the performance of your daily } \\
\text { activities to this goal }\end{array}$ \\
\hline 8 & Gratitude & $\begin{array}{l}\text { Repeat the meditations from Week } \\
\qquad 6 \text { and } 7\end{array}$ & $\begin{array}{l}\text { Gratitude Journal/Jar: write } \\
\text { down the things that you are } \\
\text { grateful for in a journal or on } \\
\text { slips of paper placed in a jar }\end{array}$ \\
\hline
\end{tabular}




\section{References}

Cho, J., \& Gifford, K. (2016). The anxious lawyer: An 8-week guide to a joyful and satisfying law practice through mindfulness and meditation. ABA Publishing.

Kabat-Zinn, J. (1982). An outpatient program in behavioral medicine for chronic pain patients based on the practice of mindfulness meditation: Theoretical considerations and preliminary results. General Hospital Psychiatry, 4(1), 33-47.

https://doi.org/10.1016/0163-8343(82)90026-3 
Supplementary Information 2: The Job Effectiveness Questionnaire

The JEQ was adapted for use in these studies from the SigmaRadius 360 Degree

Feedback system - a commercial job performance measure (Jackson, 2013) — as a way to assess one's perceived ability to effectively demonstrate various job-related competencies. Participants were presented with 27 job-related skills and were asked to rate the level of effectiveness with which they performed each skill on a scale of 1 (low) to 7 (high). If a particular behaviour was not observed, participants could indicate as much by selecting "not observed" as their response. Scores were calculated by removing any items for which the participant responded "not observed" and taking an average of the ratings across all remaining items. Scores range from $1-$ 7, with high scores indicating a high degree of workplace competency. The JEQ displayed adequate levels of internal consistency across all time points in both studies (for Study $1, \alpha=$ .91-.93; for Study 2, $\alpha=.75-.97)$.

\section{Study 1}

\section{Time 1 and 2 Comparisons}

mITT analyses $(n=45)$ revealed a significant T1 $(M=5.12, S D=.76)$ to T2 $(M=5.42$, $S D=.79$ ) increase in scores on the JEQ (see Figure 2.1); $z=-3.47, p<.001, r=.52$. Results from PP analyses $(n=44)$ were found to be comparable to the results from mITT analyses.

Figure 2.1. Distributions* of scores on the Job Effectiveness Questionnaire from the Study 1 modified intention-to-treat Time 1 (T1) and 2 (T2) comparison analyses.

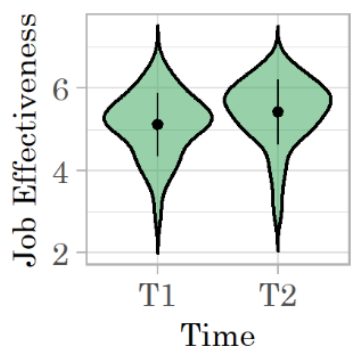

Note. Dots and whiskers represent means and standard deviations, respectively.

\section{Moderation}

Time spent meditating was not found to be a significant predictor of change on the JEQ in either mITT or PP analyses, before or after outlier removal ( $p>.05$ for all).

Study 2

\section{Comparisons Across All Three Time Points (see Supplemental Digital Content 6)}

In mITT analyses $(n=37$; see Figure 2.2), none of the effects in the $2 \times 3$ mixed ANOVA were found to be statistically significant ( $p>.05$ for all). In PP analyses $(n=36$; also depicted in Figure 2.2), neither the interaction nor the main effect of condition was found to be statistically significant ( $p>.05$ for both). The main effect of time, however, was significant, though posthocs revealed no differences between T1 $(M=5.21, S D=.62)$, T2 $(M=5.21, S D=.81)$, or T3 $(M=5.42, S D=.78)$; overall, $F(2,68)=3.48, p=.04, \eta_{\mathrm{G}}^{2}=.02$; post-hocs, $p_{\mathrm{adj}}>.05$ for all.

\section{Time 2 Comparisons}

mITT analyses $(n=64)$ revealed that, after adjusting for differences in T1 scores $\left(M_{\mathrm{G}}=\right.$ 5.26), no T2 differences on the JEQ were observed between conditions (experimental, $M_{\text {adj }}=$ 5.30, $S E=.11$; control, $M_{\text {adj }}=5.21, S E=.09 ; p>.05$; see Figure 2.3). Results from PP analyses $(n=63)$ were found to be comparable to the results from mITT analyses. 
Figure 2.2. Distributions* of scores on the Job Effectiveness Questionnaire from the Study 2 modified intention-to-treat (mITT) and per-protocol (PP) analyses comparing control (light green/grey) and experimental (dark green/grey) conditions across Time 1 (T1), 2, (T2), and 3 (T3).
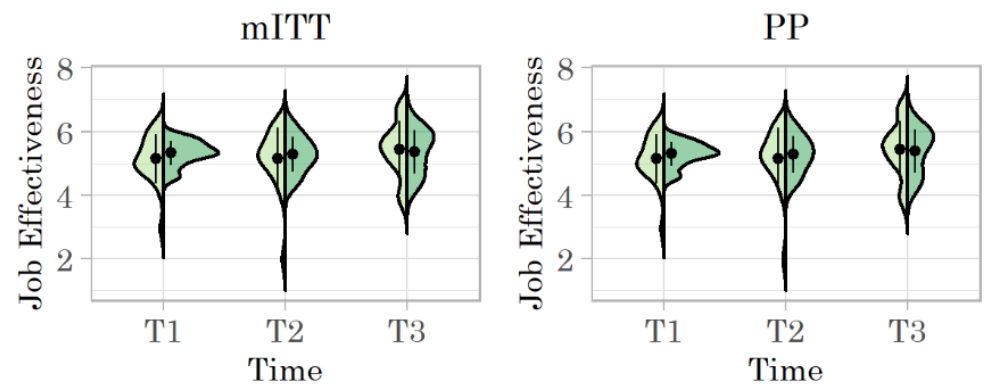

$\square$ Control $\square$ Experimental

Note. Dots and whiskers represent means and standard deviations, respectively.

Figure 2.3. Visual depiction of the modified intention-to-treat analysis of covariance test performed on the Job Effectiveness Questionnaire in Study 2.

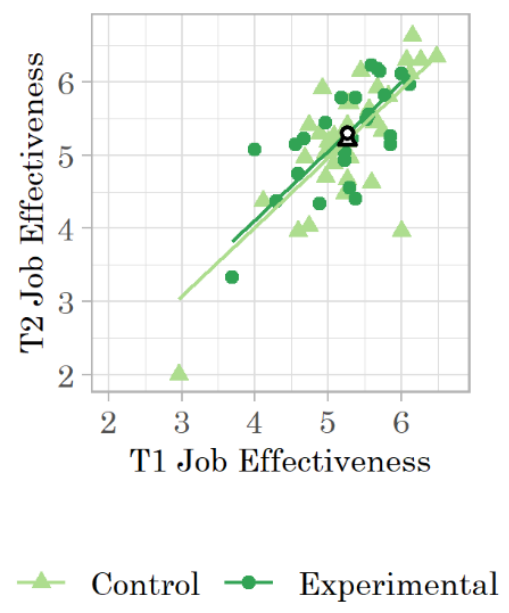

Note. Plots depict Time 2 (T2) scores as a function of both Time 1 (T1) scores and condition (control $=$ light green/grey triangles; experimental $=$ dark green/grey circles). Regression lines illustrate the models used to test for condition-specific differences in T2 scores on the Job Effectiveness Questionnaire. Open triangles and circles represent adjusted means for the control and experimental conditions, respectively. Whiskers representing the standard errors of the adjusted means are also plotted but are too small to be visible.

\section{Moderation}

mITT analyses revealed that time spent meditating was not a significant predictor of change on the JEQ prior to outlier removal; $R 2=.03, F(1,43)=1.33, p=.25, B=.003$. Following the 
removal of outliers, meditation engagement was found to be a significant moderator, such that more time spent meditating was found to be associated with more positive change (i.e., greater increases) on the JEQ (see Figure 2.4 ); $R 2=.10, F(1,41)=4.76, p=.03, B=.01$. PP analyses were found to be comparable to the results from mITT analyses.

Figure 2.4. Visual depiction of the modified intention-to-treat moderation analysis performed on the Job Effectiveness Questionnaire in Study 2.
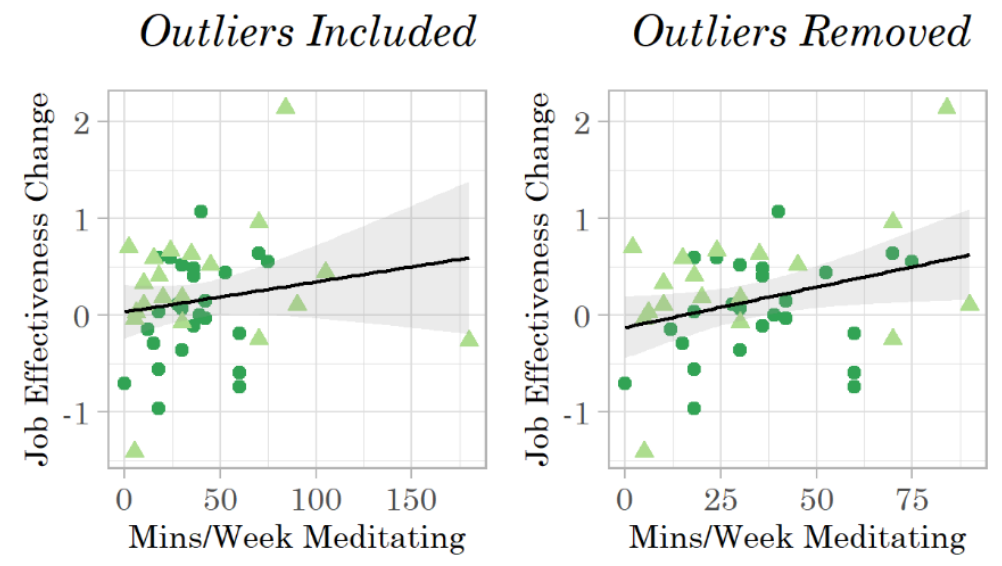

$\triangle$ Control - Experimental

Note. Figures depict the moderating relationship between minutes per week spent meditating during the intervention and changes in scores on the Job Effectiveness Questionnaire both before (left) and after (right) outlier removal. For participants in the control condition (light green/grey triangles), change was calculated as Time 3 -Time 2. For participants in the experimental condition (dark green/grey circles), change was calculated as Time 2 - Time 1 . The shaded area represents a $95 \%$ confidence region. 


\section{References}

Jackson, D. N. (2013). SigmaRadius 360 Degree Feedback. Sigma Assessment Systems, Inc.

"Score distributions are presented via violin plots, which display smoothed density distributions. Due to smoothing, distribution tails may extend beyond the possible range of scores. 
Supplementary Information 3: Depression Anxiety Stress Scales-21 Severity Categories

The DASS-21 (Lovibond \& Lovibond, 1995) specifies ranges for the purpose of classifying scores as being indicative of symptoms that are normal, mild, moderate, severe, and extremely severe. The spread of participants from the main analyses in each study across these categories is outlined in Table 3.1 below. For comparison's sake, severity data from Krill and colleagues (2016) is presented in Table 3.2.

Table 3.1. Percentage of participant responses on the Depression Anxiety Stress Scales-21 that fall in each of the symptom severity categories across both studies.

\begin{tabular}{lcccccc}
\hline & \multicolumn{2}{c}{ Depression } & \multicolumn{2}{c}{ Anxiety } & \multicolumn{2}{c}{ Stress } \\
\cline { 2 - 7 } Symptom Severity & Time 1 & Time 2 & Time 1 & Time 2 & Time 1 & Time 2 \\
\hline Normal & & \multicolumn{2}{c}{ Study $1^{\mathrm{a}}$} \\
Mild & 48.89 & 64.44 & 42.22 & 66.67 & 33.33 & 66.67 \\
Moderate & 17.78 & 13.33 & 8.89 & 13.33 & 13.33 & 8.89 \\
Severe & 15.56 & 13.33 & 31.11 & 15.56 & 17.78 & 11.11 \\
Extremely Severe & 6.67 & 6.67 & 11.11 & 2.22 & 31.11 & 11.11 \\
\hline & 11.11 & 2.22 & 6.67 & 2.22 & 4.44 & 2.22 \\
Normal & 76.92 & 79.49 & 74.36 & 64.10 & 61.54 & 71.79 \\
Mild & 5.13 & 5.13 & 7.69 & 7.69 & 10.26 & 5.13 \\
Moderate & 10.26 & 10.26 & 2.56 & 20.51 & 7.69 & 10.26 \\
Severe & 2.56 & 2.56 & 7.69 & .00 & 17.95 & 12.82 \\
Extremely Severe & 5.13 & 2.56 & 7.69 & 7.69 & 2.56 & .00 \\
\hline & \multicolumn{7}{c}{ Study } & $2-$ Experimental Condition & \\
Normal & 64.00 & 80.00 & 60.00 & 76.00 & 60.00 & 84.00 \\
Mild & 4.00 & 8.00 & 12.00 & 16.00 & 16.00 & 8.00 \\
Moderate & 16.00 & 8.00 & 20.00 & 4.00 & 12.00 & 8.00 \\
Severe & 4.00 & 4.00 & .00 & 4.00 & 12.00 & .00 \\
Extremely Severe & 12.00 & .00 & 8.00 & .00 & .00 & .00 \\
\hline
\end{tabular}

Note. Values describe participants included in the Study 1 modified intention-to-treat Time 1 and 2 comparison analyses and the Study 2 modified intention-to-treat Time 2 comparison analyses. ${ }^{\mathrm{a}} n=45 .{ }^{\mathrm{b}} n=39 .{ }^{\mathrm{c}} n=25$.

Table 3.2. Percentage of responses on the Depression Anxiety Stress Sales-21 from Krill et al. (2016) that fall in each of the symptom severity categories.

\begin{tabular}{lccc}
\hline \multicolumn{1}{c}{ Symptom Severity } & Depression $^{\mathrm{a}}$ & Anxiety $^{\mathrm{b}}$ & Stress $^{\mathrm{c}}$ \\
\hline Normal & 71.67 & 80.70 & 77.30 \\
Mild & 9.53 & 8.63 & 8.81 \\
Moderate & 10.39 & 5.01 & 8.16 \\
Severe & 4.03 & 2.53 & 4.45 \\
Extremely Severe & 4.37 & 3.14 & 1.29 \\
\hline
\end{tabular}

Note. Krill et al. (2016) did not multiply DASS-21 responses by 2. As a result, comparisons to the percentages in this table should be made with caution as the category cut-offs for nonmultiplied DASS-21 values may not be directly comparable with the cut-offs for values that have been doubled. ${ }^{\mathrm{a}} n=12,300 .{ }^{\mathrm{b}} n=12,277 .{ }^{\mathrm{c}} n=12,271$. 


\section{References}

Krill, P. R., Johnson, R., \& Albert, L. (2016). The prevalence of substance use and other mental health concerns among American attorneys. Journal of Addiction Medicine, 10(1), 46-52. https://doi.org/10.1097/ADM.0000000000000182

Lovibond, S. H., \& Lovibond, P. F. (1995). Manual for the depression anxiety stress scales (DASS) (Version 2). Psychology Foundation of Australia. 
Supplementary Information 4: Participant Characteristics

Table 4.1. Characteristics of the participants included in the Study 1 modified intention-to-treat Time 1 and 2 comparison analyses.

\begin{tabular}{lccc}
\hline \multicolumn{1}{c}{ Characteristic } & $n$ & $M$ & $S D$ \\
\hline Age (Years) & 45 & 46.00 & 11.06 \\
Years in Current Position & 45 & 8.86 & 9.14 \\
Hrs/Week Worked & 44 & 42.00 & 11.14 \\
Previous Meditation Experience (Years) & 45 & 4.83 & 11.70 \\
Meditation During the Program (Mins/Week) & 45 & 46.21 & 59.45 \\
\hline Gender & & \\
$\quad$ Male & 8 & \\
$\quad$ Female & 37 & \\
\hline Highest Level of Education & 37 & \\
Professional Degree & 6 & \\
Master's/Doctoral Degree & 2 & \\
Other & & \\
Partner & 11 & \\
Non-Partner Attorney & 19 & \\
Other & 15 & \\
Position & & \\
Am Law 200 & 9 & \\
Small Firm & 13 & \\
Solo Practitioner & 12 \\
In-House Counsel & 4 & \\
Other & 7 & \\
\hline Law Firm Type & & \\
\hline
\end{tabular}


Table 4.2. Characteristics of the participants included in the Study 2 modified intention-to-treat Time 2 comparison analyses.

\begin{tabular}{|c|c|c|c|c|c|c|c|c|c|}
\hline \multirow[b]{2}{*}{ Characteristic } & \multicolumn{3}{|c|}{ Control } & \multicolumn{3}{|c|}{ Experimental } & \multicolumn{3}{|c|}{ Overall } \\
\hline & $n$ & $M$ & $S D$ & $n$ & $M$ & $S D$ & $n$ & $M$ & $S D$ \\
\hline Age (Years) & 39 & 48.00 & 10.28 & 25 & 49.56 & 9.64 & 64 & 48.61 & 9.99 \\
\hline Years in Current Position & 39 & 9.55 & 9.20 & 23 & 12.41 & 8.42 & 62 & 10.61 & 8.96 \\
\hline Hrs/Week Worked & 39 & 50.86 & 10.74 & 25 & 49.72 & 8.33 & 64 & 50.41 & 9.82 \\
\hline Previous Meditation Experience (Years) & $37^{\mathrm{a}}$ & .67 & 2.03 & 25 & 1.72 & 4.40 & 62 & 1.09 & 3.21 \\
\hline Meditation During the Program (Mins/Week) & & $\mathrm{N} / \mathrm{A}$ & & 25 & 35.58 & 19.03 & & & \\
\hline \multicolumn{10}{|l|}{ Gender } \\
\hline Male & 11 & & & 11 & & & 22 & & \\
\hline Female & 28 & & & 14 & & & 42 & & \\
\hline \multicolumn{10}{|l|}{ Position } \\
\hline Equity Shareholder & 9 & & & 7 & & & 16 & & \\
\hline Non-Equity Shareholder & 12 & & & 10 & & & 22 & & \\
\hline Of Counsel/Counsel & 6 & & & 4 & & & 10 & & \\
\hline Associate & 10 & & & 4 & & & 14 & & \\
\hline Other & 2 & & & 0 & & & 2 & & \\
\hline \multicolumn{10}{|l|}{ Size of Home Office } \\
\hline$<10$ Employees & 0 & & & 2 & & & 2 & & \\
\hline 10 - 20 Employees & 7 & & & 4 & & & 11 & & \\
\hline$>20$ Employees & 32 & & & 19 & & & 51 & & \\
\hline
\end{tabular}

Two control participants have been excluded because they indicated that they had $3+$ years of meditation experience but failed to further specify the number of years of experience that they possessed. 
Table 4.3. Characteristics of the control participants included in the Study 2 moderation analyses.

\begin{tabular}{lccc}
\hline \multicolumn{1}{c}{ Characteristic } & $n$ & $M$ & $S D$ \\
\hline Age (Years) & 21 & 48.52 & 11.08 \\
Years in Current Position & 21 & 8.69 & 9.67 \\
Hrs/Week Worked & 21 & 51.71 & 8.50 \\
Previous Meditation Experience (Years) $^{\mathrm{a}}$ & 19 & .20 & .47 \\
Meditation During the Program (Mins/Week) & 21 & 40.95 & 44.76 \\
\hline Gender & 7 & \\
$\quad$ Male & 14 & \\
$\quad$ Female & & \\
Position & 4 & \\
$\quad$ Equity Shareholder & 5 & \\
Non-Equity Shareholder & 2 & \\
Of Counsel/Counsel & 8 & \\
Associate & 2 & \\
Other & & \\
10 - 20 Employees & 2 & \\
$\quad>20$ Employees & 19 & \\
\hline Size of Home Office & & \\
\hline
\end{tabular}

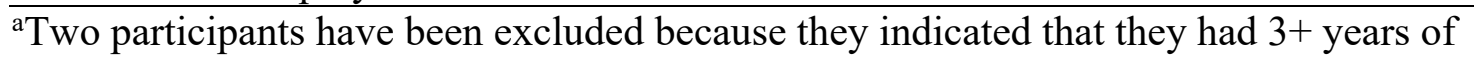
meditation experience but failed to further specify the number of years of experience that they possessed. 


\section{Supplementary Information 5: Figures}

Figure 5.1. Distributions* of scores on each of the outcome measures from the Study 1 modified intention-to-treat Time 1 (T1) and 2 (T2) comparison analyses.

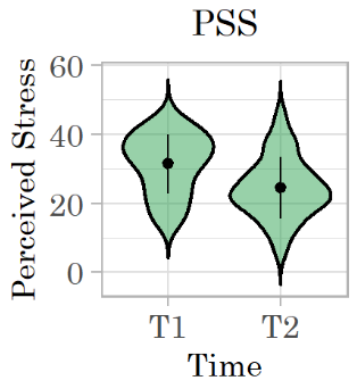

FFMQ-24

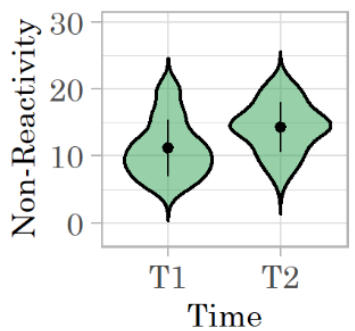

FFMQ-24

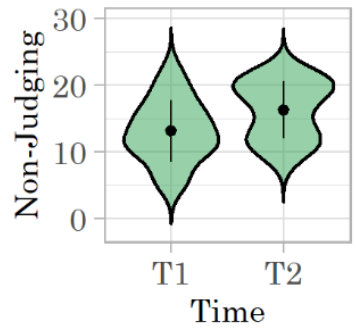

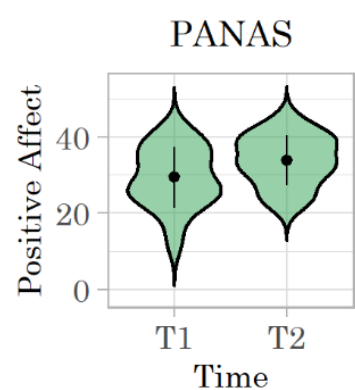

FFMQ-24

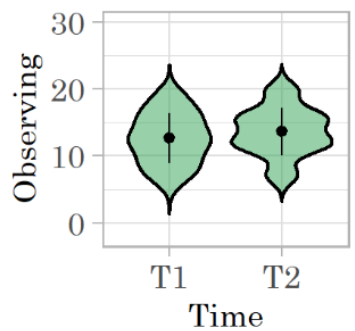

DASS-21

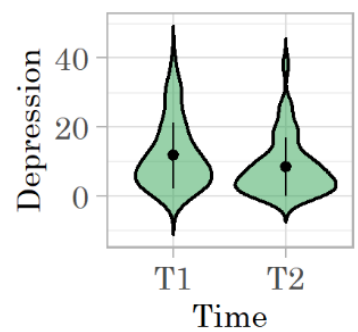

PANAS

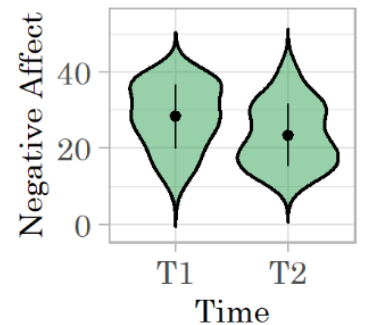

FFMQ-24

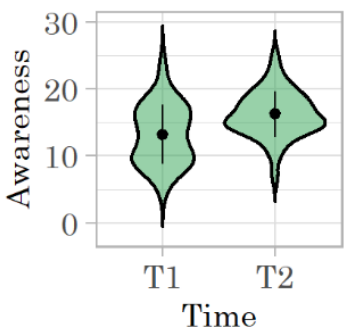

DASS-21

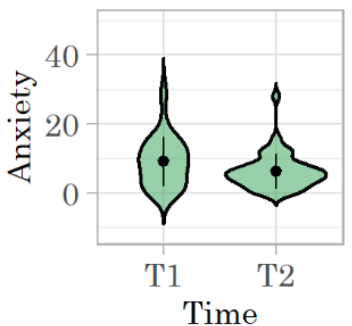

BRS

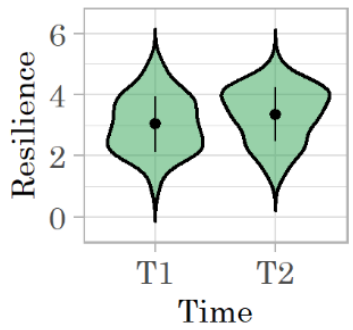

FFMQ-24

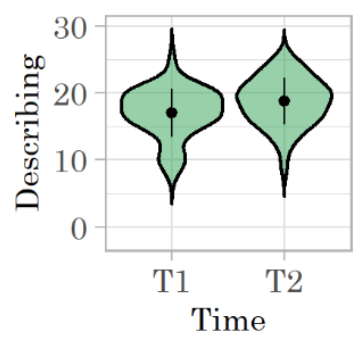

DASS-21

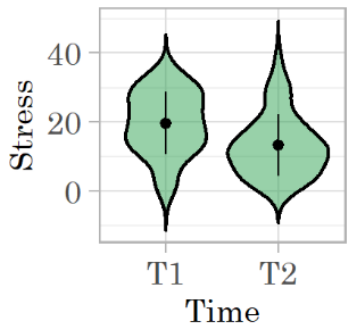

Note. Distributions depict scores from the Perceived Stress Scale (PSS); the positive and negative affect subscales of the Positive and Negative Affect Schedule (PANAS); the Brief Resilience Scale (BRS); the non-reactivity, observing, awareness, describing, and non-judging subscales of the Five Facet Mindfulness Questionnaire-24 (FFMQ-24); and the depression, anxiety, and stress subscales of the Depression Anxiety Stress Scales-21 (DASS-21). Dots and whiskers represent means and standard deviations, respectively. 
Figure 5.2. Visual depictions of the modified intention-to-treat analysis of covariance tests from Study 2.

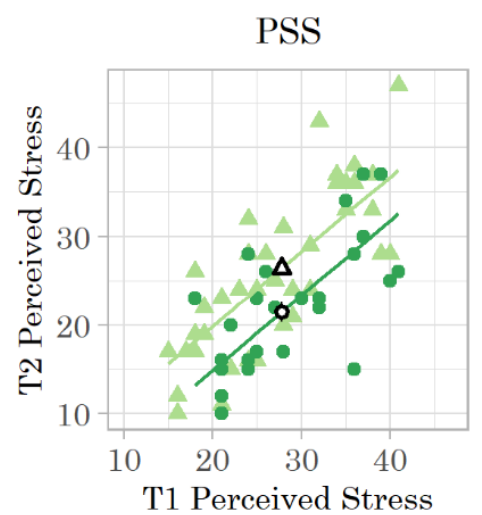

BRS

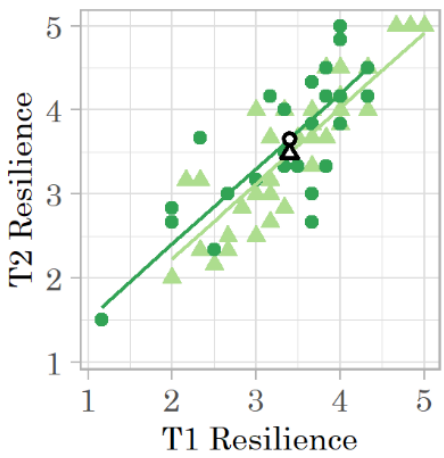

PANAS

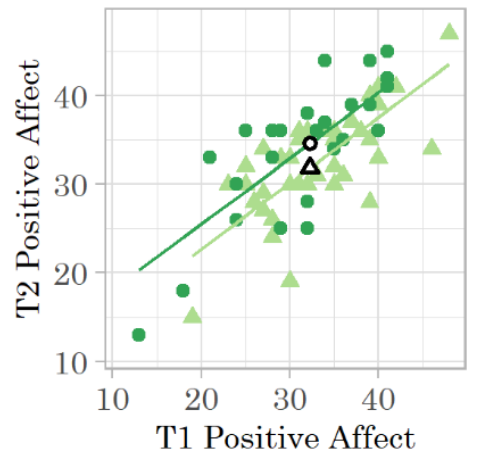

FFMQ-24

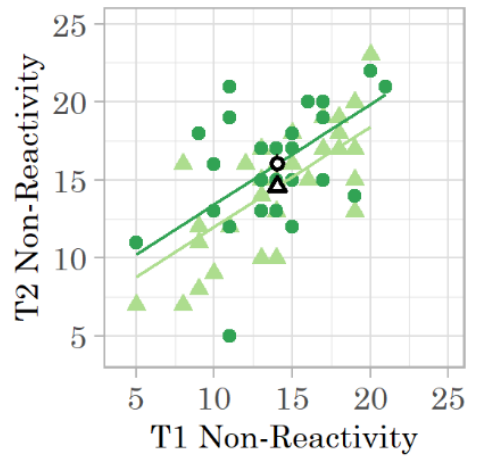

PANAS

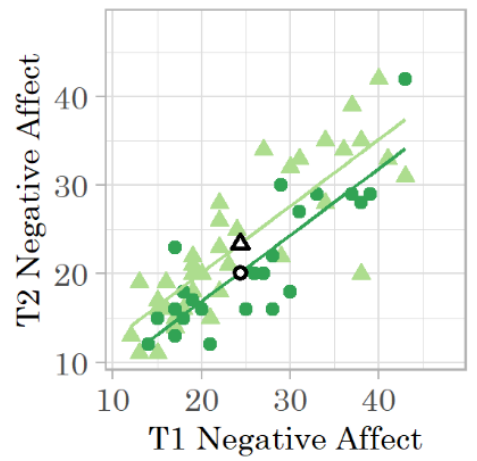

FFMQ-24

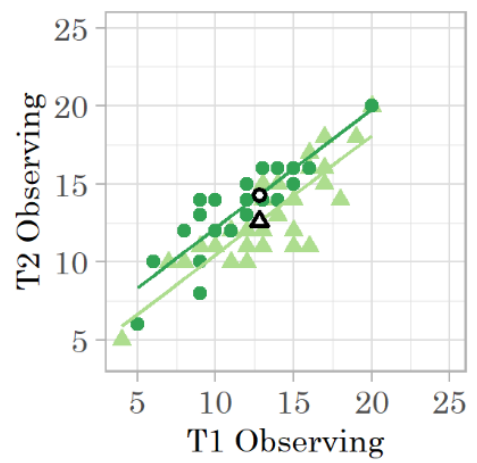

(Continued on the next page.) 
(Figure 5.2 continued.)

FFMQ-24

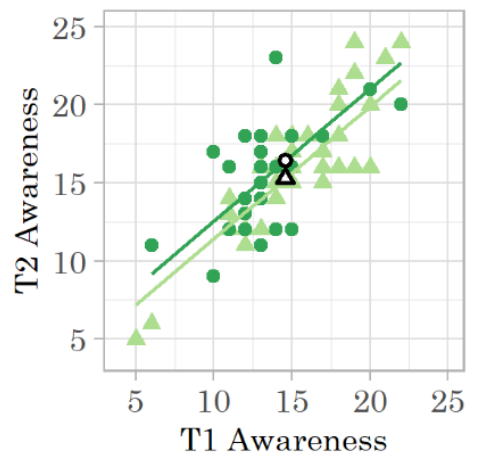

FFMQ-24

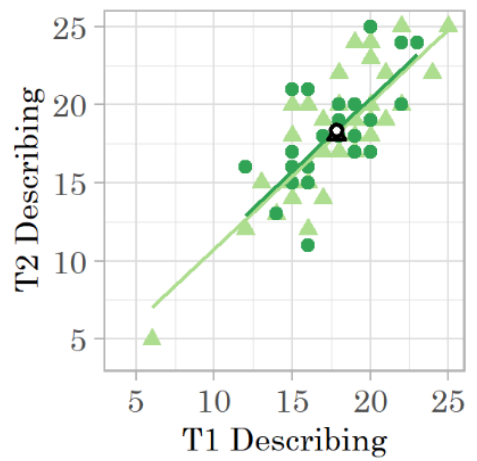

Control $\rightarrow$ Experimental
DASS-21

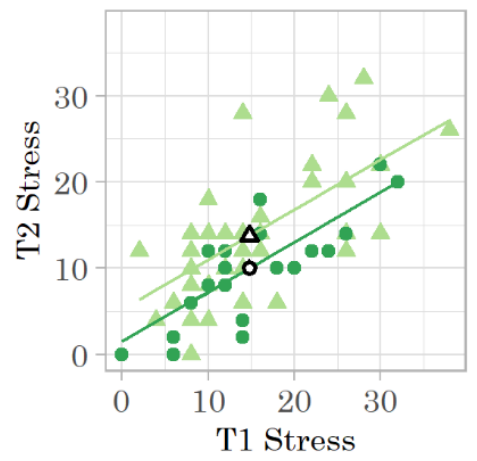

Note. Plots depict Time 2 (T2) scores as a function of both Time 1 (T1) scores and condition (control = light green/grey triangles; experimental $=$ dark green/grey circles). Regression lines illustrate the models used to test for condition-specific differences in T2 scores on the Perceived Stress Scale (PSS); the positive and negative affect subscales of the Positive and Negative Affect Schedule (PANAS); the Brief Resilience Scale (BRS); the non-reactivity, observing, awareness, and describing subscales of the Five Facet Mindfulness Questionnaire-24 (FFMQ-24); and the stress subscale of the Depression Anxiety Stress Scales-21 (DASS-21). Open triangles and circles represent adjusted means for the control and experimental conditions, respectively. Whiskers representing the standard errors of the adjusted means are also plotted but are too small to be visible. 
Figure 5.3. Visual depictions of the modified intention-to-treat Yuen's tests from Study 2.

FFMQ-24

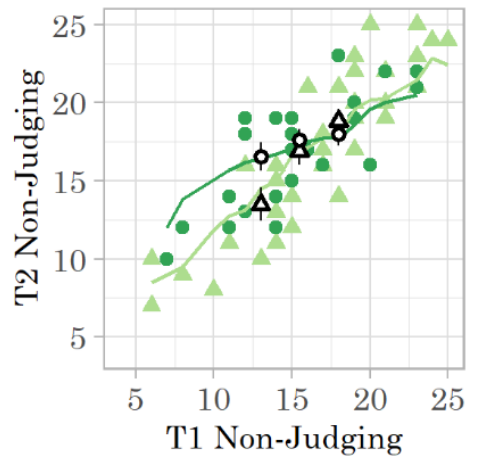

T1 Non-Judging
DASS-21

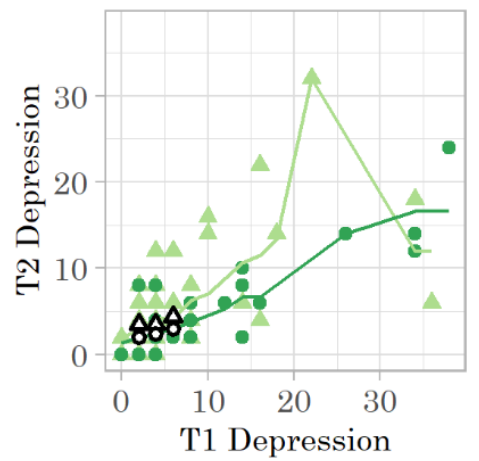

$\sim$ Control $\rightarrow$ Experimental

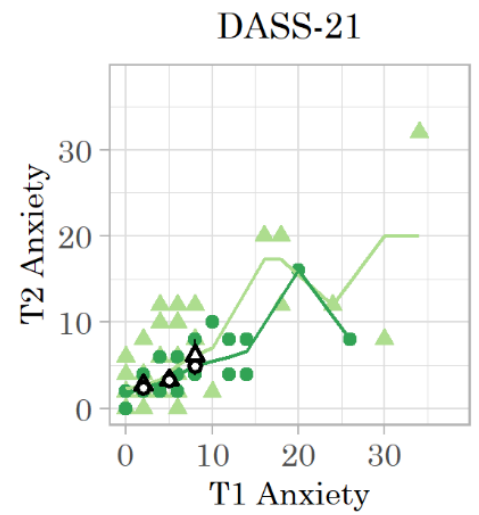

T1 Anxiety

Note. Plots depict Time 2 (T2) scores as a function of both Time 1 (T1) scores and condition (control $=$ light green/grey triangles; experimental $=$ dark green/grey circles). Nonparametric regression lines illustrate the results of running interval trimmed mean smoothing functions that have been applied to scores on the non-judging subscale of the Five Facet Mindfulness Questionnaire-24 (FFMQ-24) and the depression and anxiety subscales of the Depression Anxiety Stress Scales-21 (DASS-21). Open triangles and circles represent the comparison points (i.e., local trimmed means of the control and experimental conditions, respectively) used to test for condition-specific differences in T2 scores at certain levels of T1; whiskers represent standard errors of the trimmed means. 
Figure 5.4. Visual depictions of regressions from the modified intention-to-treat moderation analyses from Study 2.

\section{Outliers Included Outliers Removed}

Perceived Stress Scale
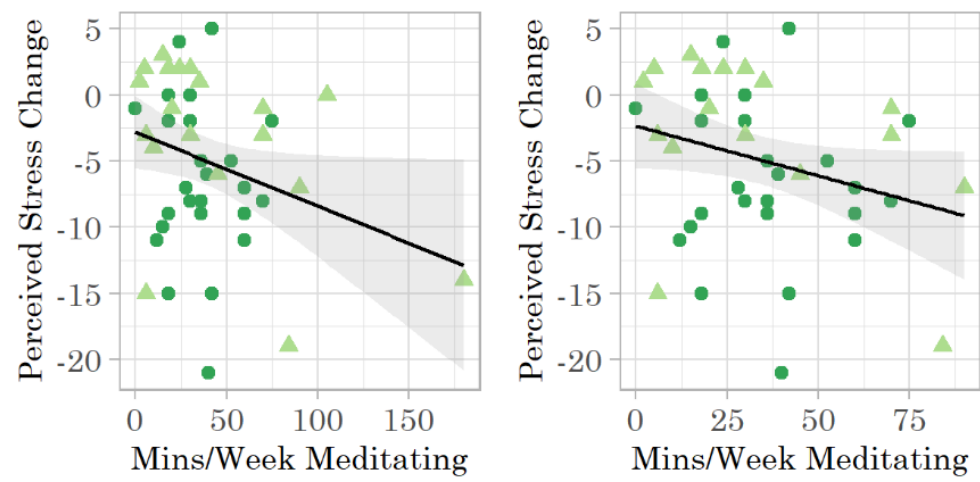

Five Facet Mindfulness Questionnaire-24
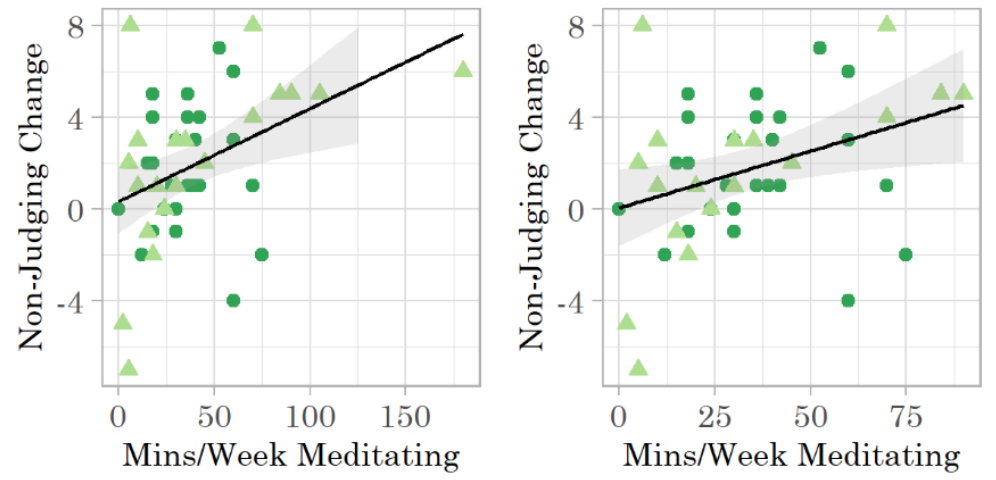

Depression Anxiety Stress Scales-21
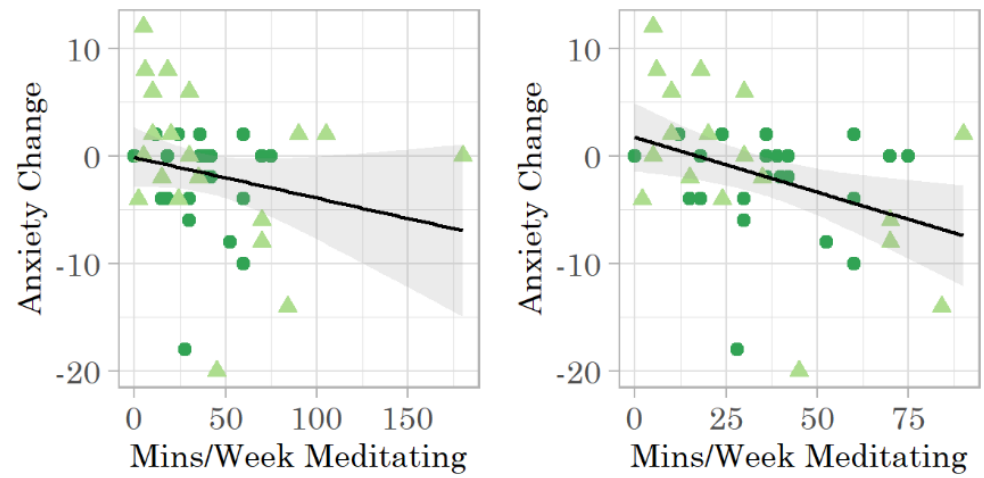

(Continued on the next page.) 
(Figure 5.4 continued.)

\section{Outliers Included $\quad$ Outliers Removed}

Depression Anxiety Stress Scales-21
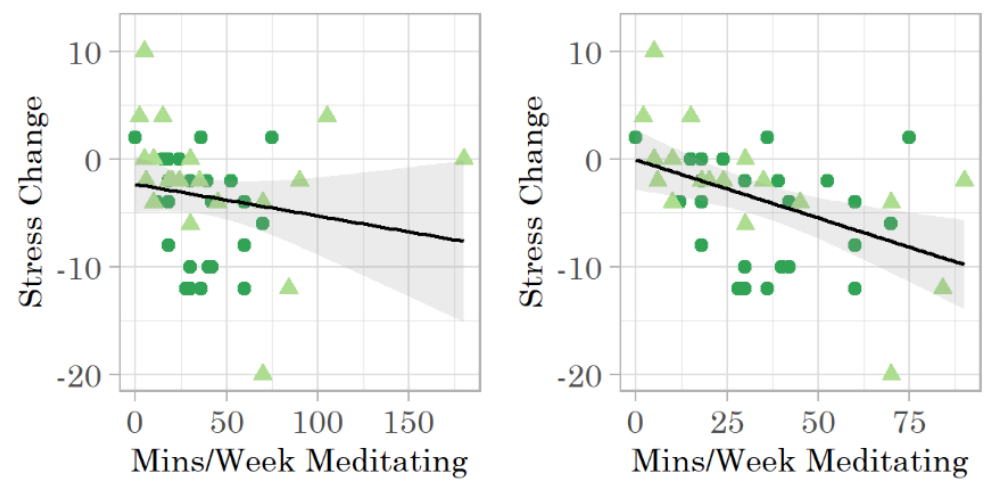

$\triangle$ Control Experimental

Note. Figures depict the moderating relationship between minutes per week spent meditating during the intervention and changes in scores on the Perceived Stress Scale, the non-judging subscale of the Five Facet Mindfulness Questionnaire-24, and the anxiety and stress subscales of the Depression Anxiety Stress Scales-21 both before (left) and after (right) outlier removal. For participants in the control condition (light green/grey triangles), change was calculated as Time 3 - Time 2. For participants in the experimental condition (dark green/grey circles), change was calculated as Time 2 - Time 1 . The shaded area represents a 95\% confidence region. 
Figure 5.5. Visual depictions of the per-protocol analysis of covariance tests from Study 2.
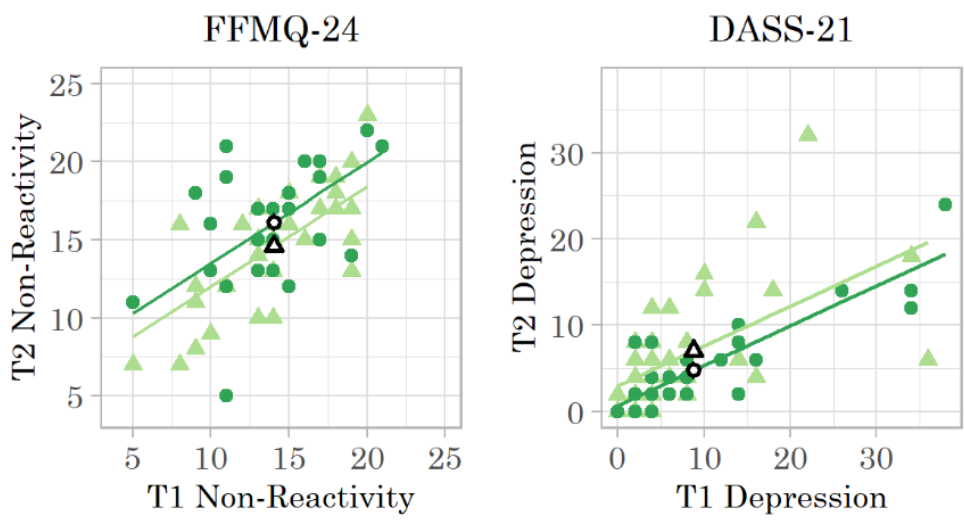

$\rightarrow$ Control $\rightarrow$ Experimental

Note. Plots depict Time 2 (T2) scores as a function of both Time 1 (T1) scores and condition (control $=$ light green/grey triangles; experimental $=$ dark green/grey circles). Regression lines illustrate the models used to test for condition-specific differences in T2 scores on the nonreactivity subscale of the Five Facet Mindfulness Questionnaire-24 (FFMQ-24) and the depression subscale of the Depression Anxiety Stress Scales-21 (DASS-21). Open triangles and circles represent adjusted means for the control and experimental conditions, respectively. Whiskers representing the standard errors of the adjusted means are also plotted but are too small to be visible. 
Figure 5.6. Visual depiction of the per-protocol Yuen's test from Study 2.

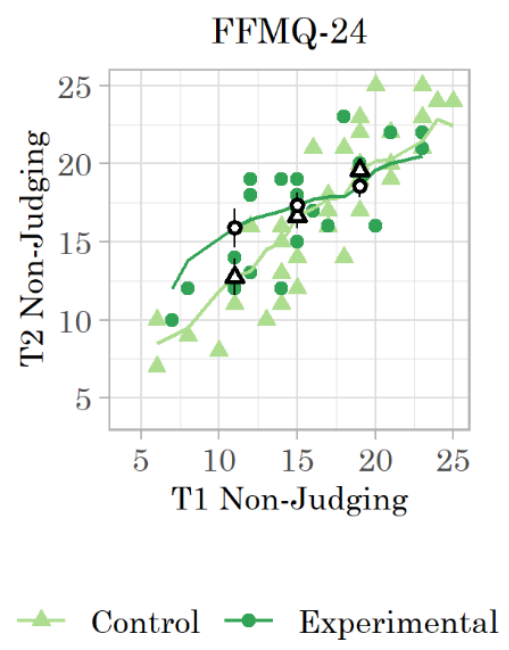

Note. Plot depicts Time 2 (T2) scores as a function of both Time 1 (T1) scores and condition (control $=$ light green/grey triangles; experimental $=$ dark green/grey circles). Nonparametric regression lines illustrate the results of running interval trimmed mean smoothing functions that have been applied to scores on the non-judging subscale of the Five Facet Mindfulness Questionnaire-24 (FFMQ-24). Open triangles and circles represent the comparison points (i.e., trimmed means of the control and experimental conditions, respectively) used to test for condition-specific differences in $\mathrm{T} 2$ scores at certain levels of $\mathrm{T} 1$; whiskers represent standard errors of the trimmed means. 
Figure 5.7. Visual depiction of a regression from the per-protocol moderation analyses from Study 2.

\section{Outliers Included}

Perceived Stress Scale

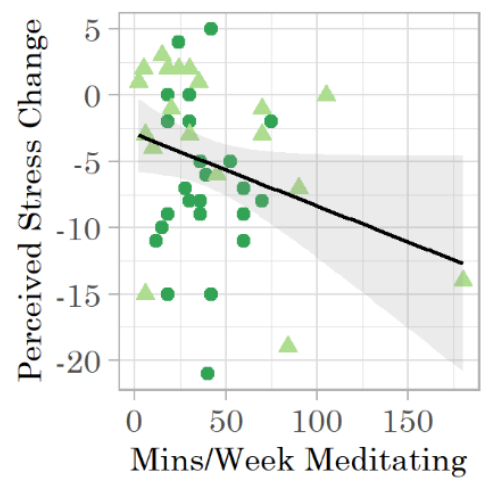

$\Delta$ Control - Experimental

Note. The figure depicts the moderating relationship between minutes per week spent meditating during the intervention and changes in scores on the Perceived Stress Scale before outlier removal. For participants in the control condition (light green/grey triangles), change was calculated as Time 3 - Time 2. For participants in the experimental condition (dark green/grey circles), change was calculated as Time 2 - Time 1 . The shaded area represents a $95 \%$ confidence region.

*Score distributions are presented via violin plots, which display smoothed density distributions. Due to smoothing, distribution tails may extend beyond the possible range of scores. 
Supplementary Information 6: Study 2 Comparisons Across All Three Time Points

In line with an analysis plan registered on OSF, 2 x 3 mixed ANOVAs were conducted for each measure with condition as a between-group factor and time as a within-group factor. In cases of heteroscedasticity (assessed via a Levene's test), white corrections were applied. Sphericity violations (assessed via Mauchly's test for sphericity) were addressed with epsilon corrections - as suggested by Girden (1992), a Greenhouse-Geisser correction was applied when the Greenhouse-Geisser epsilon estimate was less than .75 and, when it was greater than .75, a Huynh-Feldt correction was used. Significant interactions were assessed via Holm-Bonferronicorrected tests of simple main effects (i.e., the main effect of time was assessed for each condition separately using corrected one-way ANOVAs) and significant main effects were followed by Holm post-hoc tests.

\section{Participant Attrition}

As discussed in the Time 2 Comparisons section, the T1 to T2 attrition rate was $31.18 \%$. Of the 64 participants $\left(n_{\text {Experimental }}=25\right)$ who responded to both the T1 and T2 surveys, 38 $\left(n_{\text {Experimental }}=18\right)$ provided responses to the T3 survey, resulting in a T2 to T3 attrition rate of $40.63 \%$. An independent $t$-test indicated that the 38 participants who responded to all three assessments $(M=50.50, S D=9.85)$ were significantly older than the 57 participants who responded to only one or two of the assessments $(M=44.86, S D=8.82) ; t(92)=-2.90, p=.005$, $d=-.61$.

\section{Modified Intention-to-Treat Analyses}

One participant in the control condition was omitted from analyses involving the FFMQ24 and the DASS-21 because they failed to respond to these scales in the T3 assessment. Consequently, $n=38$ or 37 for the mITT analyses $(n$ Experimental $=18)$; characteristics of these 38 participants are presented in Table 6.1. None of the characteristics differed significantly across conditions among these participants (all $p>.05$ ). Score distributions for each outcome measure are presented in Figure 6.1. Internal consistency of the DASS-21 anxiety subscale was found to be low among participants in the experimental condition, with $\alpha$ ranging from .34-.64 across the three time points. All other internal consistency values were found to be generally adequate $(\alpha=$ $.66-.96)$.

\section{Perceived Stress Scale}

Neither the interaction nor the main effect of condition was found to be statistically significant $(p>.05$ for both). The main effect of time, however, was significant; $F(2,72)=$ $17.70, p<.001, \eta_{\mathrm{G}}^{2}=.08$. Post-hocs further revealed that both $\mathrm{T} 2(M=24.55, S D=9.19)$ and $\mathrm{T} 3$ $(M=22.42, S D=7.21)$ scores on the PSS were significantly lower than T1 scores $(M=28.08$, $S D=7.63) ; p_{\text {adj }}=.003$ and $p_{\text {adj }}<.001$, respectively. T3 scores were also found to be significantly lower than T2 scores; $p_{\text {adj }}=.04$.

\section{Positive and Negative Affect Schedule}

Positive Affect. None of the effects were found to be statistically significant with respect to scores on the positive affect subscale of the PANAS ( $p>.05$ for all).

Negative Affect. Scores on the negative affect subscale of the PANAS displayed violations of the assumptions of both homoscedasticity and sphericity. A white correction was, therefore, applied to the test of condition and an epsilon correction $\left(\varepsilon_{\mathrm{HF}}=.78\right)$ was applied to the interaction and to the test of time. Neither the interaction nor the main effect of condition were found to be statistically significant ( $p>.05$ for both). The main effect of time, however, was significant; $F(1.56,55.99)=10.92, p<.001, \eta_{\mathrm{G}}^{2}=.04$. Post-hocs further revealed that both $\mathrm{T} 2$ $(M=21.76, S D=8.23)$ and $\mathrm{T} 3(M=20.37, S D=7.03)$ scores were significantly lower than $\mathrm{T} 1$ 
Table 6.1. Study 2 participant characteristics.

\begin{tabular}{|c|c|c|c|c|c|c|c|c|c|}
\hline \multirow[b]{2}{*}{ Characteristics } & \multicolumn{3}{|c|}{ Control } & \multicolumn{3}{|c|}{ Experimental } & \multicolumn{3}{|c|}{ Overall } \\
\hline & $n$ & $M$ & $S D$ & $n$ & $M$ & $S D$ & $n$ & $M$ & $S D$ \\
\hline Age (Years) & 20 & 49.15 & 10.98 & 18 & 52.00 & 8.47 & 38 & 50.50 & 9.85 \\
\hline Years in Current Position & 20 & 8.88 & 9.88 & 17 & 12.35 & 8.71 & 37 & 10.47 & 9.40 \\
\hline Hrs/Week Worked & 20 & 51.30 & 8.50 & 18 & 48.50 & 7.19 & 38 & 49.97 & 7.93 \\
\hline Previous Meditation Experience (Years) & $18^{\mathrm{a}}$ & .19 & .49 & 18 & 2.07 & 5.15 & 36 & 1.13 & 3.73 \\
\hline Meditation During the Program (Mins/Week) & 20 & 38.50 & 44.45 & 18 & 34.56 & 19.01 & 38 & 36.63 & 34.42 \\
\hline \multicolumn{10}{|l|}{ Continued Meditation After Program Completion } \\
\hline Yes (Mins/Week) & \multirow{2}{*}{\multicolumn{3}{|c|}{ N/A }} & 8 & 16.32 & 20.12 & & & \\
\hline No & & & & 10 & & & & & \\
\hline \multicolumn{10}{|l|}{ Gender } \\
\hline Male & 6 & & & 6 & & & 12 & & \\
\hline Female & 14 & & & 12 & & & 26 & & \\
\hline \multicolumn{10}{|l|}{ Position } \\
\hline Equity Shareholder & 4 & & & 5 & & & 9 & & \\
\hline Non-Equity Shareholder & 5 & & & 8 & & & 13 & & \\
\hline Of Counsel/Counsel & 2 & & & 3 & & & 5 & & \\
\hline Associate & 7 & & & 2 & & & 9 & & \\
\hline Other & 2 & & & 0 & & & 2 & & \\
\hline \multicolumn{10}{|l|}{ Size of Home Office } \\
\hline$<10$ Employees & 0 & & & 2 & & & 2 & & \\
\hline 10 - 20 Employees & 2 & & & 2 & & & 4 & & \\
\hline$>20$ Employees & 18 & & & 14 & & & 32 & & \\
\hline
\end{tabular}

Note. Values describe participants included in the Study 2 modified intention-to-treat analyses comparing across all three time points. ${ }^{a}$ Two control participants have been excluded because they indicated that they had $3+$ years of meditation experience but failed to further specify the number of years of experience that they possessed. 
Figure 6.1. Distributions* of scores on each of the outcome measures from Study 2.

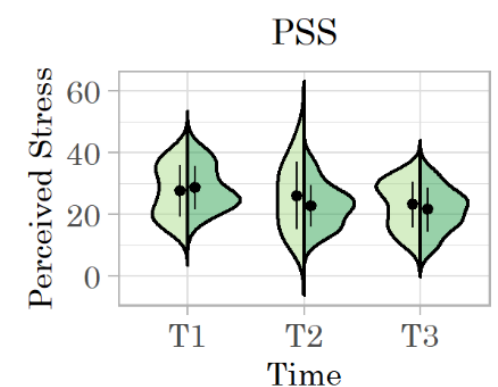

BRS

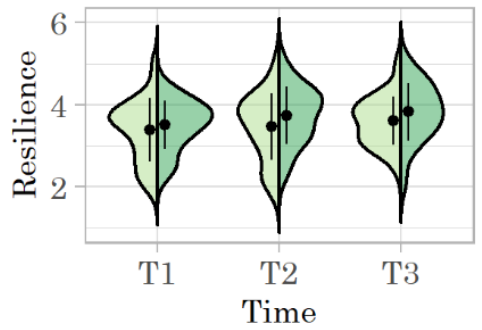

FFMQ-24

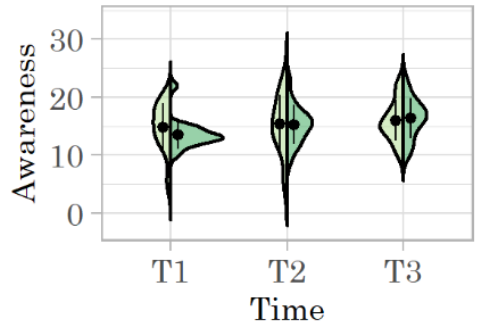

PANAS

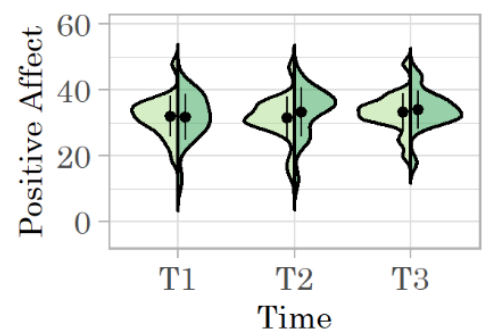

FFMQ-24

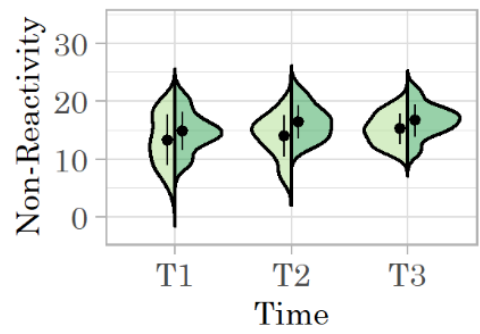

FFMQ-24

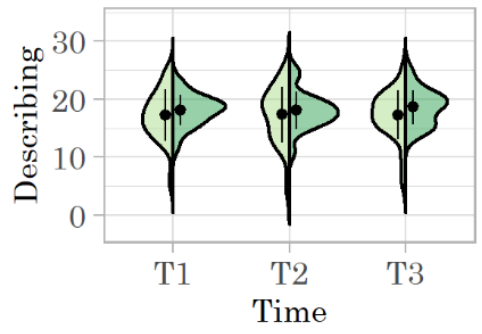

PANAS

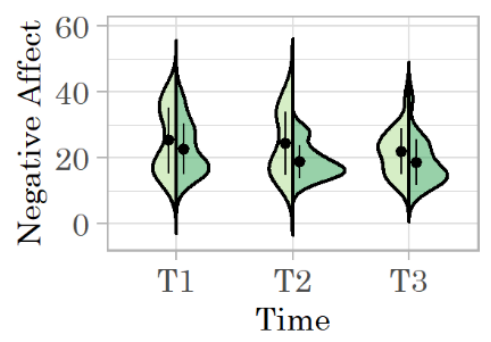

FFMQ-24

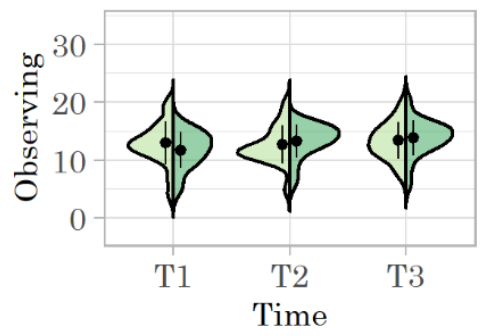

FFMQ-24

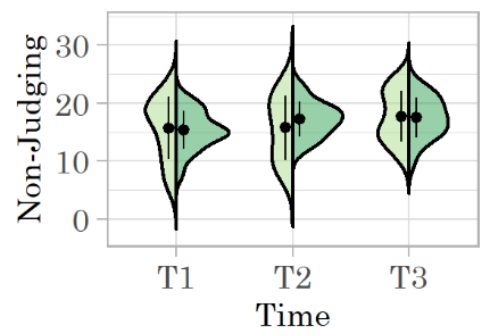

(Continued on the next page.)

scores $(M=24.11, S D=8.96) ; p_{\text {adj }}=.002$ for both. A significant score difference was not observed between T2 and T3 ( $\left.p_{\text {adj }}>.05\right)$.

\section{Brief Resilience Scale}

Neither the interaction nor the main effect of condition was found to be statistically significant ( $p>.05$ for both). The main effect of time, however, was significant; $F(2,72)=5.65$, $p=.01, \eta_{\mathrm{G}}^{2}=.03$. Post-hocs further revealed that T3 scores $(M=3.71, S D=.65)$ on the BRS were significantly higher than $\mathrm{T} 1$ scores $(M=3.44, S D=.68) ; p_{\text {adj }}=.002$. Significant score differences were not observed between T1 and T2 $(M=3.60, S D=.65)$ or T2 and T3 ( $p_{\text {adj }}>.05$ for both).

\section{Five Facet Mindfulness Questionnaire-24}

Non-Reactivity. Neither the interaction nor the main effect of condition was found to be statistically significant ( $p>.05$ for both). The main effect of time, however, was significant; $F(2$, $70)=7.17, p=.002, \eta_{\mathrm{G}}^{2}=.05$. Post-hocs further revealed that $\mathrm{T} 3$ scores $(M=15.92, S D=2.78)$ on the non-reactivity subscale of the FFMQ-24 were significantly higher than T1 scores $(M=$ $14.03, S D=3.93) ; p_{\text {adj }}=.01$. Significant score differences were not observed between $\mathrm{T} 1$ and $\mathrm{T} 2$ $(M=15.14, S D=3.49)$ or T2 and T3 ( $p_{\text {adj }}>.05$ for both). 


\section{(Figure 6.1 continued.)}

DASS-21

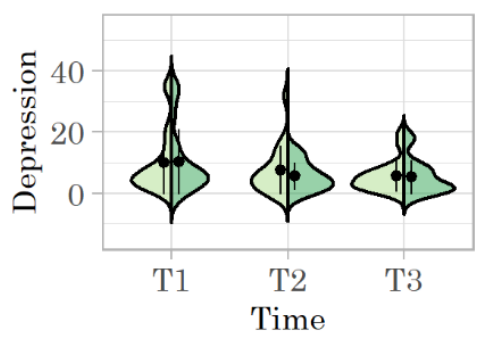

DASS-21

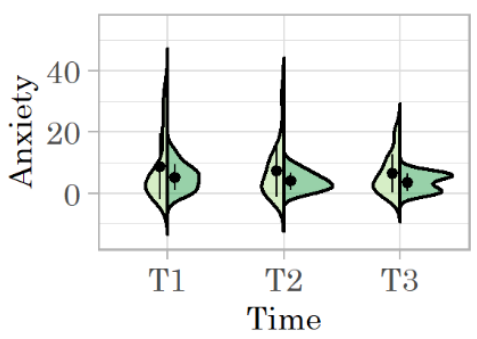

DASS-21

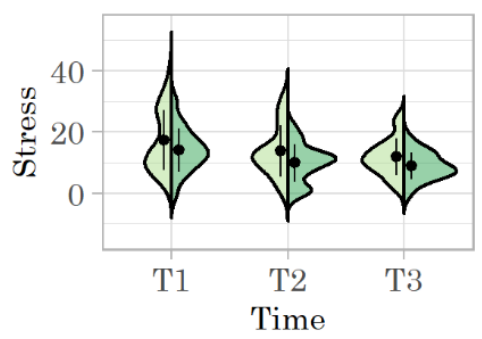

$\lceil$ Control $\square$ Experimental

Note. Distributions are from the Study 2 modified intention-to-treat analyses comparing control (light green/grey) and experimental (dark green/grey) conditions across Time 1 (T1), 2 (T2), and 3 (T3). Distributions are shown for the Perceived Stress Scale (PSS); the positive and negative affect subscales of the Positive and Negative Affect Schedule (PANAS); the Brief Resilience Scale (BRS); the non-reactivity, observing, awareness, describing, and non-judging subscales of the Five Facet Mindfulness Questionnaire-24 (FFMQ-24); and the depression, anxiety, and stress subscales of the Depression Anxiety Stress Scales-21 (DASS-21). Dots and whiskers represent means and standard deviations, respectively.

Observing. Scores on the observing subscale of the FFMQ-24 displayed a violation of the assumption of sphericity. An epsilon correction $\left(\varepsilon_{\mathrm{GG}}=.75\right)$ was, therefore, applied to the interaction and to the test of time. Neither the interaction nor the main effect of condition were found to be statistically significant ( $p>.05$ for both). The main effect of time, however, was significant; $F(1.50,52.34)=4.98, p=.02, \eta_{\mathrm{G}}^{2}=.03$. Post-hocs further revealed that T3 scores $(M$ $=13.59, S D=3.08)$ were significantly higher than T1 scores $(M=12.35, S D=3.45) ; p_{\text {adj }}=.04$. Significant score differences were not observed between T1 and T2 $(M=12.95, S D=3.09)$ or T2 and T3 ( $p_{\text {adj }}>.05$ for both).

Acting with Awareness. Neither the interaction nor the main effect of condition was found to be statistically significant ( $p>.05$ for both). The main effect of time, however, was significant; $F(2,70)=9.00, p<.001, \eta_{\mathrm{G}}^{2}=.05$. Post-hocs further revealed that both $\mathrm{T} 2(M=$ $15.35, S D=4.22)$ and $\mathrm{T} 3(M=16.16, S D=3.45)$ scores on the awareness subscale of the FFMQ-24 were significantly higher than T1 scores $(M=14.16, S D=3.52) ; p_{\text {adj }}=.01$ and $p_{\text {adj }}<$ .001 , respectively. A significant score difference was not observed between T2 and T3 ( $p_{\text {adj }}>$ $.05)$.

Describing. None of the effects were found to be statistically significant with respect to scores on the describing subscale of the FFMQ-24 ( $p>.05$ for all).

Non-Judging. Scores on the non-judging subscale of the FFMQ-24 displayed a violation of the assumption of homoscedasticity. A white correction was, therefore, applied to the test of condition. Neither the interaction nor the main effect of condition was found to be statistically significant ( $p>.05$ for both). The main effect of time, however, was significant; $F(2,70)=9.31$, $p<.001, \eta_{\mathrm{G}}^{2}=.04$. Post-hocs further revealed that $\mathrm{T} 3$ scores $(M=17.62, S D=3.93)$ were 
significantly higher than T1 scores $(M=15.51, S D=4.46) ; p_{\text {adj }}=.001$. Significant score differences were not observed between T1 and T2 $(M=16.49, S D=4.49)$ or T2 and T3 ( $p_{\text {adj }}>$ .05 for both).

\section{Depression Anxiety Stress Scales-21}

The spread of participants across each of the DASS-21 severity categories is outlined in Table 6.2.

Depression. Scores on the depression subscale of the DASS-21 displayed a violation of the assumption of sphericity. An epsilon correction $\left(\varepsilon_{\mathrm{HF}}=.88\right)$ was, therefore, applied to the interaction and to the test of time. Neither the interaction nor the main effect of condition were found to be statistically significant ( $p>.05$ for both). The main effect of time, however, was significant; $F(1.76,61.47)=8.98, p<.001, \eta_{\mathrm{G}}^{2}=.06$. Post-hocs further revealed that both T2 $(M$ $=6.59, S D=6.46)$ and T3 $(M=5.51, S D=5.30)$ scores were significantly lower than T1 scores $(M=10.16, S D=10.35) ; p_{\text {adj }}=.02$ and $p_{\text {adj }}<.001$, respectively. A significant score difference was not observed between T2 and T3 ( $\left.p_{\text {adj }}>.05\right)$.

Anxiety. Scores on the anxiety subscale of the DASS-21 displayed a violation of the assumption of homoscedasticity. A white correction was, therefore, applied to the test of condition. None of the effects were found to be statistically significant ( $p>.05$ for all).

Stress. Neither the interaction nor the main effect of condition was found to be statistically significant ( $p>.05$ for both). The main effect of time, however, was significant; $F(2$, $70)=17.03, p<.001, \eta_{\mathrm{G}}^{2}=.09$. Post-hocs further revealed that both $\mathrm{T} 2(M=11.95, S D=7.62)$ and T3 $(M=10.43, S D=5.46)$ scores were significantly lower than $\mathrm{T} 1$ scores $(M=15.78, S D=$ $8.69) ; p_{\text {adj }}<.001$ for both. A significant score difference was not observed between T2 and T3 $\left(p_{\text {adj }}>.05\right)$.

\section{Per-Protocol Analyses}

Of the 38 participants who responded to all three assessments, one in the experimental condition indicated that they did not meditate at all throughout the program. For PP analyses, therefore, $n=$ 37 or $36\left(n_{\text {Experimental }}=17\right)$. PP analyses deviated from mITT analyses with respect to both the PSS and the observing subscale of the FFMQ-24 (see Figure 6.2). All other results from PP analyses were comparable to results from mITT analyses.

\section{Perceived Stress Scale}

As in mITT analyses, PP analyses revealed that both T2 $(M=24.30, S D=9.18)$ and T3 $(M=22.43, S D=7.31)$ scores on the PSS were significantly lower than T1 scores $(M=27.89$, $S D=7.65) ; p_{\text {adj }}=.003$ and $p_{\text {adj }}<.001$, respectively. Unlike mITT analyses, however, PP analyses revealed no significant difference between T2 and T3 scores $\left(p_{\text {adj }}>.05\right)$. PP results regarding the interaction and the main effect of condition were comparable to mITT results.

\section{Five Facet Mindfulness Questionnaire-24}

Observing. Scores on the observing subscale displayed a violation of the assumption of sphericity. An epsilon correction $\left(\varepsilon_{\mathrm{GG}}=.73\right)$ was, therefore, applied to the interaction and to the test of time. Unlike mITT analyses, PP analyses exhibited a significant interaction; $F(1.47$, $49.84)=3.83, p=.04, \eta_{\mathrm{G}}^{2}=.02$. Tests of simple main effects-which also employed epsilon corrections (experimental, $\varepsilon_{\mathrm{GG}}=.67$; control, $\varepsilon_{\mathrm{GG}}=.73$ ) - found a significant main effect of time for the experimental condition; $F(1.41,22.54)=9.65, p_{\text {adj }}=.005, \eta_{\mathrm{G}}^{2}=.10$. The main effect of time was not significant for the control condition ( $\left.\mathrm{p}_{\text {adj }}>.05\right)$. Post-hocs further revealed that, for participants in the experimental condition, both $\mathrm{T} 2(M=13.59, S D=2.62)$ and T3 $(M=14.12$, $S D=2.91)$ scores were significantly higher than T1 scores $(M=11.88, S D=3.12) ; p_{\text {adj }}<.001$ 
Table 6.2. Percentage of participant responses on the Depression Anxiety Stress Scales-21 that fall in each of the symptom severity categories in Study 2.

\begin{tabular}{|c|c|c|c|c|c|c|c|c|c|}
\hline \multirow[b]{2}{*}{ Symptom Severity } & \multicolumn{3}{|c|}{ Depression } & \multicolumn{3}{|c|}{ Anxiety } & \multicolumn{3}{|c|}{ Stress } \\
\hline & Time 1 & Time 2 & Time 3 & Time 1 & Time 2 & Time 3 & Time 1 & Time 2 & Time 3 \\
\hline & \multicolumn{9}{|c|}{ Control Condition $^{\mathrm{a}}$} \\
\hline Normal & 65.00 & 70.00 & 84.21 & 60.00 & 55.00 & 63.16 & 55.00 & 70.00 & 73.68 \\
\hline Mild & 10.00 & 5.00 & 5.26 & 10.00 & 5.00 & 5.26 & 5.00 & .00 & 15.79 \\
\hline Moderate & 10.00 & 20.00 & 10.53 & .00 & 25.00 & 21.05 & 5.00 & 15.00 & 10.53 \\
\hline Severe & 5.00 & .00 & .00 & 15.00 & .00 & .00 & 30.00 & 15.00 & .00 \\
\hline \multirow[t]{2}{*}{ Extremely Severe } & 10.00 & 5.00 & .00 & 15.00 & 15.00 & 10.53 & 5.00 & .00 & .00 \\
\hline & \multicolumn{9}{|c|}{ Experimental Condition $^{\mathrm{b}}$} \\
\hline Normal & 72.22 & 77.78 & 83.33 & 66.67 & 83.33 & 94.44 & 55.56 & 83.33 & 94.44 \\
\hline Mild & .00 & 11.11 & 5.56 & 16.67 & 11.11 & 5.56 & 22.22 & 11.11 & 5.56 \\
\hline Moderate & 11.11 & 11.11 & 11.11 & 16.67 & 5.56 & .00 & 16.67 & 5.56 & .00 \\
\hline Severe & 5.56 & .00 & .00 & .00 & .00 & .00 & 5.56 & .00 & .00 \\
\hline Extremely Severe & 11.11 & .00 & .00 & .00 & .00 & .00 & .00 & .00 & .00 \\
\hline
\end{tabular}

Note. Values describe participants included in the modified intention-to-treat analyses comparing across all three time points. ${ }^{a}$ at Time 1 and $2, n=20$; at Time $3, n=19 .{ }^{\mathrm{b}} n=18$. 
Figure 6.2. Distributions* of scores on the Perceived Stress Scale (PSS) and the observing subscale of the Five Facet Mindfulness Questionnaire-24 (FFMQ-24) from Study 2.
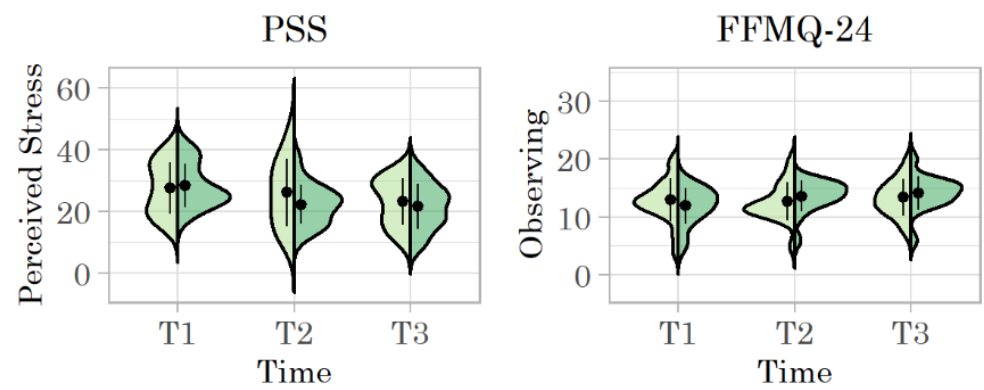

$\lceil$ Control $\square$ Experimental

Note. Distributions depict scores from the per-protocol analyses comparing control (light green/grey) and experimental (dark green/grey) conditions across Time 1 (T1), 2 (T2), and 3 (T3). Dots and whiskers represent means and standard deviations, respectively.

and $p_{\text {adj }}=.01$, respectively. A significant experimental score difference was not observed between T2 and T3 ( $\left.p_{\text {adj }}>.05\right)$. 


\section{References}

Girden, E. R. (1992). ANOVA: Repeated measures. Sage.

*Score distributions are presented via violin plots, which display smoothed density distributions. Due to smoothing, distribution tails may extend beyond the possible range of scores. 